\title{
A novel mechanism for telomere size control in Saccharomyces cerevisiae
}

\author{
Bibo $\mathrm{Li}^{1}$ and Arthur J. Lustig ${ }^{1,2,3}$ \\ ${ }^{1}$ Graduate Program in Molecular Biology, Cornell University Graduate School of Medical Sciences, New York, New York \\ 10021 USA, and ${ }^{2}$ Molecular Biology Program, Sloan-Kettering Institute, Memorial Sloan-Kettering Cancer Center, New \\ York, New York 10021 USA
}

One of the central requirements for eukaryotic chromosome stability is the maintenance of the simple sequence tracts at telomeres. In this study, we use genetic and physical assays to reveal the nature of a novel mechanism by which telomere length is controlled. This mechanism, telomeric rapid deletion (TRD), is capable of reducing elongated telomeres to wild-type tract length in an apparently single-division process. The deletion of telomeres to wild-type lengths is stimulated by the hpr1 mutation, suggesting that TRD in these cells is the consequence of an intrachromatid pathway. Paradoxically, TRD is also dependent on the lengths of the majority of nonhomologous telomeres in the cell. Defects in the chromatin-organizing protein Sir3p increase the rate of hpr1-induced rapid deletion and specifically change the spectrum of rapid deletion events. We propose a model in which interactions among telosomes of nonhomologous chromosomes form higher order complexes that restrict the access of the intrachromatid recombination machinery to telomeres. This mechanism of size control is distinct from that mediated through telomerase and is likely to maintain telomere length within a narrow distribution.

[Key Words: Telomeres; telomeric size control; telomeric associations; HPR1; SIR3]

Received February 15, 1996; revised version accepted April 15, 1996.

Telomeres, the unique protein-DNA structures present at the termini of linear eukaryotic chromosomes, participate in two critical roles: as substrates for a unique nonDNA templated mechanism of end replication /Greider 1995), and as caps to protect the chromosomes from degradation and rearrangement (Zakian 1995a). Telomeres also confer effects on transcription, replication, and chromatin structure in adjacent domains (Shore 1995; Zakian 1995a).

In most organisms, telomeric DNA is composed of simple-sequence G+T-rich DNA, with the G-rich strand oriented in a $5^{\prime} \rightarrow 3^{\prime}$ direction toward the terminus (Zakian 1995a). The enzyme responsible for addition of these simple sequences is telomerase, a ribonucleoprotein that adds telomeric sequences onto the G-rich strand using a sequence within the RNA component as template (Greider 1995). Following G-strand synthesis, the complementary strand is likely to be replicated by lagging-strand synthesis coupled with a mechanism for generating a new 3' overhang (Zahler and Prescott 1988; Lingner et al. 1995). In most organisms, telomeric tract size of even an individual chromosomal end varies among different cells of a population. Nevertheless, telomere size is regulated, because telomeric tracts cluster within a discrete distribution of sizes (Walmsley and Petes 1985; Shampay and Blackburn 1988).

The processes that maintain telomere tract sizes within a discrete distribution are poorly understood. The importance of size regulation is underscored by the in-

${ }^{3}$ Corresponding author. viability caused by grossly elongated telomeres in the budding yeast Kluyveromyces lactis (McEachern and Blackburn 1995). In principle, this process may involve factors that either limit the processivity of telomerase or truncate the elongated telomeres to their original length.

Telomere size control has been studied extensively in the yeast Saccharomyces cerevisiae. The structure of the yeast telomere is typical of most eukaryotes, except that the repeat unit of the telomere is irregular, following the consensus sequence $(\mathrm{TG})_{1-6} \mathrm{TG}_{2-3}$ (Zakian 1995b). The mean length of these tracts, termed $\mathrm{TG}_{1-3}$ tracts, ranges from 150 to $800 \mathrm{bp}$ in different strains, with individual telomeres maintained in a genetically determined equilibrium centered around an average length (Walmsley and Petes 1985; Shampay and Blackburn 1988; Zakian 1995b). The recent characterization of the RNA component of telomerase (Singer and Gottschling 1994) and the detection of telomerase activity (Cohn and Blackburn 1995; Lin and Zakian 1995; Lue and Wang 1995) indicate that telomerase is also used to synthesize telomeric repeats in yeast.

One of the principal components that regulates telomeric $\mathrm{TG}_{1-3}$ tract size is the essential and abundant DNA-binding protein Raplp (Shore 1994; Gilson and Gasser 1995). Raplp-binding sites reside in a variety of genomic loci, including multiple upstream activating sequences, the silencer elements within $H M L$ and $H M R$, and the telomeric $\mathrm{TG}_{1-3}$ tracts. At telomeres, high-affinity $\mathrm{Rap} 1 \mathrm{p}$-binding sites are present at an average density of 1 site per $18 \mathrm{bp}$ of telomeric sequence (Longtine et al. 1989; Gilson et al. 1993). 
The fact that Raplp is present at the telomere in vivo is indicated by the association of Raplp with telomeric chromatin fractions (termed the telosomel, and by immunocytochemical localization of Raplp to telomeric regions in meiotic cells (Conrad et al. 1990; Klein et al. 1992; Wright et al. 1992). Furthermore, in mitotic cells, Raplp-telomeric complexes cluster at sites near the nuclear periphery (Palladino et al. 1993). Genetic studies have shown that Raplp has multiple functions in the regulation of telomere size, chromosome stability, and telomeric silencing (Shore 1994; Gilson and Gasser 1995; Zakian 1995b).

Truncation of the terminal 144-165 amino acids from the 827-amino-acid Raplp in three mutant alleles (rap117, rap1-18, and rap1-19, collectively termed the rap $1^{t}$ alleles|, has extreme effects on telomere size and stability, although DNA binding efficiency and specificity are unaltered (Kyrion et al. 1992). These Raplp mutants lack the carboxy-terminal sites that are required for association with the silencer regulatory proteins Sir $3 p$ and Sir $4 p$ (Moretti et al. 1994). Each rap $1^{t}$ mutation results in uncontrolled telomere elongation. Telomeres attain sizes up to $4 \mathrm{~kb}$ longer than the $\sim 300$-bp wild-type telomeric tract and are highly unstable. Although individual telomeres in wild-type cells vary by only 100 bp in size, telomeres of rap $1^{t}$ cells can differ by $>2 \mathrm{~kb}$ after only 25 generations of growth.

Interestingly, rap $1^{t}$ telomeres are also capable of rapid single-division loss of part or all of the increased tract sequences. These telomeric rapid deletion (TRD) events are unlike most processes that act to shorten telomeric tracts, which remove only several base pairs per generation. TRD acts stochastically: A deletion event at one telomere does not predict an event at another (Kyrion et al. 1992/. Interestingly, a similar deletion process has been observed under specialized conditions in trypanosomes and ciliates (Bernards et al. 1983; Roth and Prescott 1985; Larson et al. 1987), as well as at individual telomeres in an immortalized human cell line (Murnane et al. 1994). Thus, this deletion process may be shared among a wide range of eukaryotes and play a common role in telomere size regulation.

In this study, we use a novel genetic assay coupled with physical assays to explore the nature of rapid deletion in wild-type cells. We find that wild-type cells are capable of efficiently processing elongated telomeres to wild-type tract length, suggesting that rapid deletion may play a role in telomere size control. We present evidence that two processes contribute to TRD: intrachromatid recombination and a mechanism that measures telomeres relative to one another.

\section{Results}

Elongated telomeres introduced into wild-type cells can be restored to wild-type length through TRD

Previously, we have identified and characterized TRD in cells containing the rap $1^{t}$ alleles. These apparently single-division events are unlike most processes that act on telomeres, which result in a slow progressive loss of te- lomeric sequences. To determine whether TRD can occur in wild-type cells, we introduced elongated telomeres into a wild-type strain. Cells carrying one of the rap $1^{t}$ alleles, rap1-17, that produces elongated telomeres, including an elongated $A D E 2-$ marked telomere on the left arm of chromosome VII (VIIL), were mated to wildtype RAP1 cells. Wild-type spore colonies containing the elongated $A D E 2$-marked telomere were recovered among the meiotic progeny. These strains contain, on average, $50 \%$ of telomeres at wild-type size and $50 \%$ of telomeres elongated to varying extents. The majority of such telomeres remain elongated for $>100$ generations, exhibiting only a slow loss of sequence (data not shown; see Fig. 6 and 7, below). We frequently observed, however, colonies derived from single cells containing a mixture of the elongated telomere and a species migrating close to (i.e. within $200 \mathrm{bp}$ ) or at wild-type tract length (Fig. 1A). As in rap $1^{t}$ alleles, these deletions represent loss of telomeric tract, rather than alterations in subtelomeric sequences (data not shown). The majority (86/ 102) of deletion events produce telomeres of approximately wild-type length, with the remainder of deletion events resulting in telomeres of intermediate size. Similar results were obtained at a URA3-marked telomere on the right arm of chromosome $\mathrm{V}$ and at the naturally occurring left telomere of chromosome III /data not shown). The fraction of deleted species of higher molecular weight may represent short-lived TRD intermediates or TRD events of altered precision.

Serial liquid subculturing (Fig. 1B; see Materials and methods/ demonstrated a similar processing to telomere tract sizes close to wild-type without a visible for sufficiently long-lived) intermediate form. These data indicate that wild-type cells are capable of rapid deletion events that differ in precision from those previously observed in rap $1^{t}$ cells. The precision of TRD in wild-type cells (defined here as its fidelity) raises the possibility that rapid deletion may be a general pathway participating in telomere size control.

To determine whether analogous rapid increases in telomere size also take place in wild-type cells, the ADE2marked telomere was replaced with a URA3-marked telomere in a wild-type strain in which an average of $50 \%$ of the telomeres were elongated (see Materials and methods). The newly formed URA3-marked telomeres reattained wild-type 300 -bp $\mathrm{TG}_{1-3}$ tracts and did not alter even after extensive growth (data not shown). These data indicate that a high rate of reciprocal recombination or gene conversion between short and elongated telomeres does not take place. Rare increases in the size of elongated ADE2-marked telomeres have, however, been observed (e.g., lanes 4, 5; Fig. 3A, below), but occur at a very low rate relative to TRD ( 6 events/254 assayed). This experiment also demonstrates that wild-type telomeres do not use the elongated nonhomologous telomeres as a ruler to measure tract length.

\section{Genetic characterization of telomeric rapid deletion}

To monitor telomeric rapid deletion more easily, we de- 

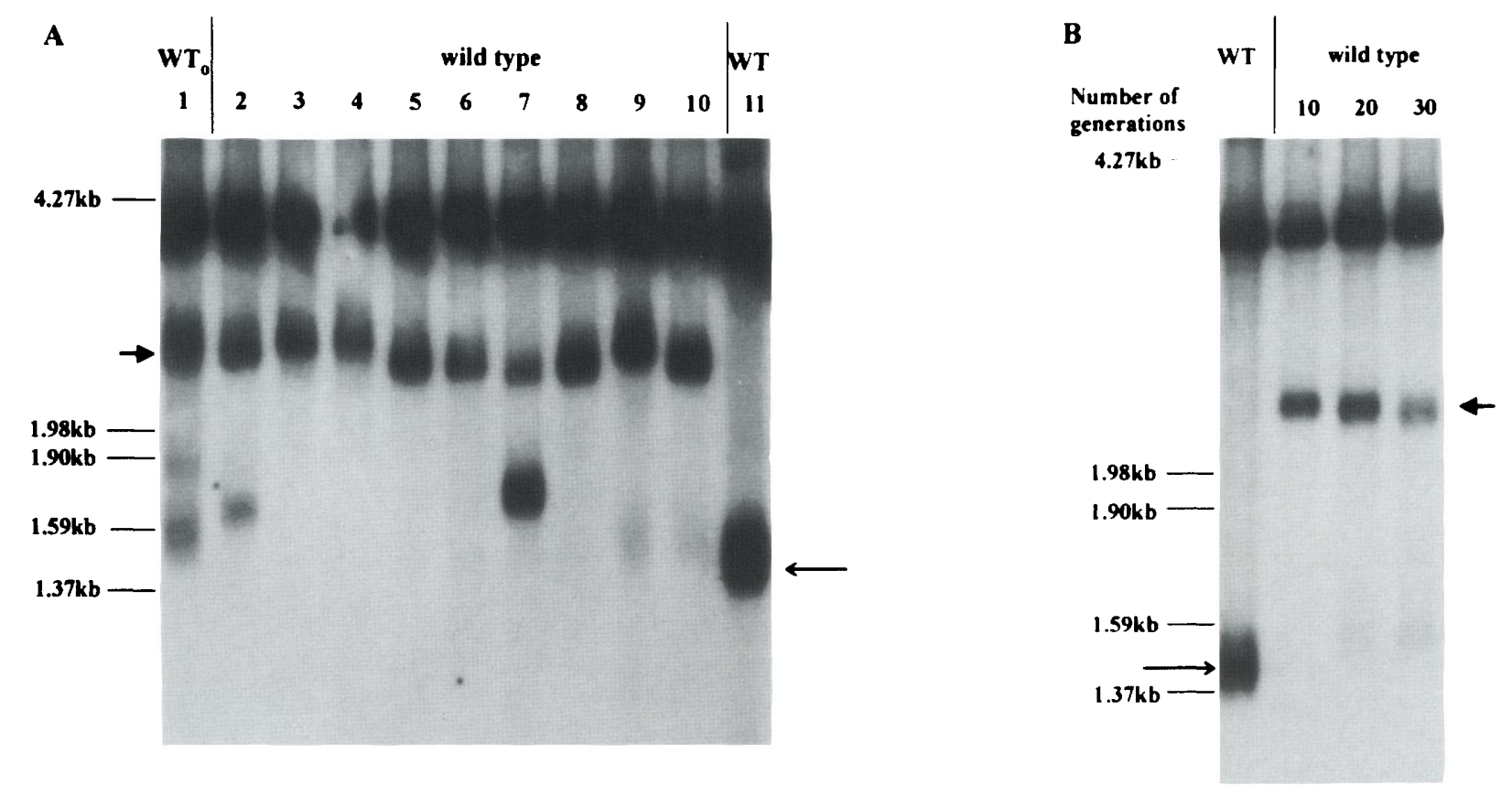

Figure 1. TRD in wild-type cells. $|A|$ NdeI-digested DNAs from nine wild-type single colonies carrying an elongated $A D E 2-m a r k e d$ telomere $\left(B L 22-2 b\right.$, lanes 2-10) were hybridized with $A D E 2$ sequences. The progenitor strain $\left(\mathrm{WT}_{\mathrm{o}}\right)$, from which the colonies in lanes 2-10 were derived, is shown in lane 1. The wild-type strain AIL275-2a-VIIL-ADE, carrying a wild-type length ADE2-marked telomere $(\sim 300 \mathrm{bp} ; \mathrm{WT})$, is shown in lane $11 .(B)$ DNA was isolated from wild-type RAP1 cells, carrying an elongated $A D E 2$-marked telomere (BL27-11a), which were subcultured in liquid YPAD medium continuously for three rounds, with each round consisting of $\sim 10$ generations of growth. DNA was isolated and treated as described above. In both $A$ and $B$, the long arrows indicate the normal wild-type VIIL telomere length, whereas the short arrows indicate the position of the elongated $A D E 2-$ marked telomere. The 4.2-kb fragment in this and other figures is an internal $A D E 2$-hybridizing species.

signed a simple color assay. Elongated telomeres introduced into a wild-type strain hyper-repress telomere-adjacent genes (Kyrion et al. 1993). We reasoned, therefore, that rare fully derepressed colonies might represent cells with a deleted telomeric tract.

To test this hypothesis, we compared the sectoring patterns of wild-type strains containing normal and elongated ADE2-marked telomeres (Fig. 2). The repressed $\mathrm{Ade}^{-}$state is monitored by the accumulation of a red pigment resulting in red colonies (or sectors). In contrast, the derepressed state is monitored by the formation of white colonies (or sectors). Wild-type cells containing telomeres of normal length ( $300 \mathrm{bp}$ ) produce fully white colonies $(80 \%)$ and white colonies with red sectors $(18 \%)$, with only a small fraction forming red colonies $(2 \%)$. In contrast, wild-type cells that carry a 900-bp $A D E 2-$ marked telomere form red and white sectored colonies. Only a small fraction of cells $(<1 \%)$ forms completely white colonies. Nonsectored white colonies identified in strains containing the elongated $A D E 2$-marked telomere might, therefore, represent rapid deletion events that restore wild-type tract lengths.

To prove this relationship, we analyzed tract lengths from both sectored colonies and nonsectored white colonies in wild-type cells. All red colonies contain elongated ADE2-marked VIIL telomeres (Fig. 3A). Similarly, the majority of white colonies with red sectors contains the elongated telomere (data not shown). In striking con- trast, the vast majority of nonsectored white colonies contain $A D E 2$-marked VIIL telomeres close to wild-type length (Fig. 3B). Because telomeres of wild-type size cannot occur through slow attrition of tract during the period of colony growth, the frequency of white colonies represents an estimate of the rapid deletion frequency. This frequency may be an underestimate, as the switch from red to white color following TRD appears to require several generations (data not shown).

We determined the TRD rate to be $1.2 \times 10^{-3}$ and $5.4 \times 10^{-3} /$ cell division in wild-type haploid and diploid cells, respectively (Table 1). An $\sim 840$-bp TG Th-3 $_{1}$ tract, 540 bp larger than that found in the wild-type W303 background used in these studies, is sufficient to yield maximal TRD frequencies.

By use of this assay, we tested the involvement of different classes of recombination and genome instability pathways in TRD through a mutational analysis. Among the mutations tested were those affecting repeated element recombination (rad52, rad1, hpr1, hpr5), mismatch repair and polymerase slippage (pms1, msh2, msh3, rth1, rad5), topoisomerases (top1, top3), telomere size control (tlc1, tel1, est1), and telomeric silencing (sir2, sir3, sir4). The response of rapid deletion to these mutations was highly specific, with most mutations (except those discussed below) having TRD frequencies not significantly different from wild-type (data not shown).

These studies implicated several genes in TRD. One of 
WILD TYPE LENGTH OF TELOMERE TRACT: The $A D E 2$ gene is weakly repressed

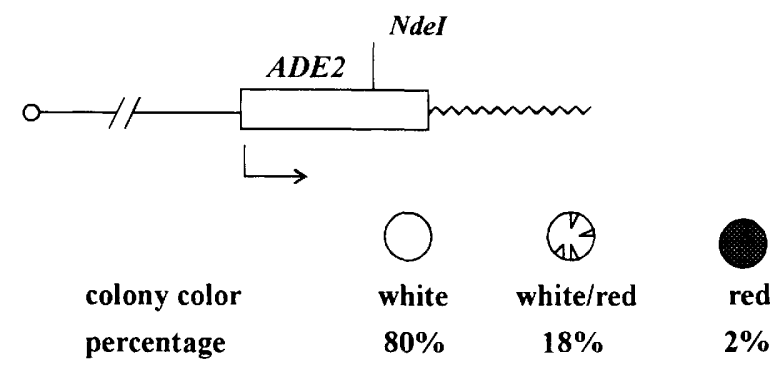

ELONGATED TELOMERE TRACT: The $A D E 2$ gene is highly repressed

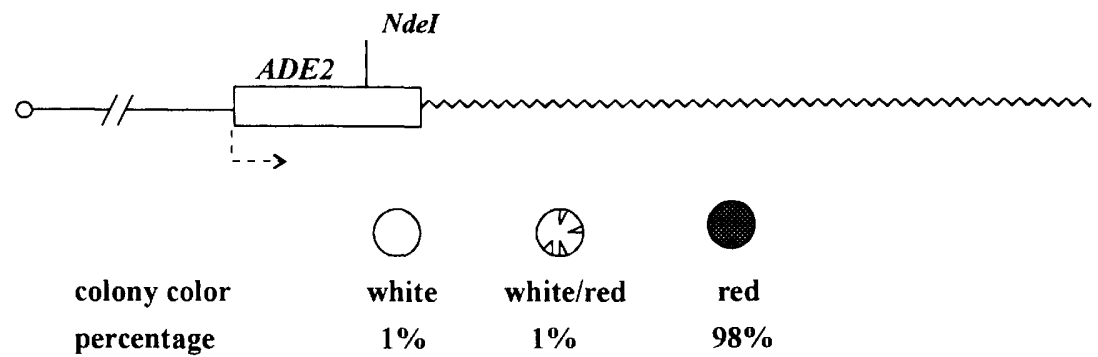

Figure 2. Construction of color assay for TRD. Diagram of color assay used to assay TRD. The NdeI site used to detect telomere tract size is also shown.

these, $R A D 52$, is primarily required for double-strandbreak mediated recombination and is essential for mitotic intrachromosomal gene conversion (Petes et al. 1991). The rad52 null allele causes a small, but clearly significant, threefold decrease in rapid deletion rates ( Table 1). Hence, whereas a RAD52-mediated recombinational pathway plays a role in TRD /either directly or indirectly), rapid deletion cannot be mediated solely through intra- or interchromosomal gene conversion. In contrast, loss of the well-defined Radlp/Rad $10 p$ endonuclease, involved in the single-strand annealing pathway (Bardwell et al. 1994), does not decrease the frequency of rapid deletion (Table 1).

\section{The hpr1 mutation enhances RAD52-dependent TRD}

The most dramatic effect of any mutation tested was exhibited by the hyper-recombination mutation hpr 1 . hpr1 null mutations result in an $\sim 10$-fold increase in TRD rate (Table 1 ). This result is intriguing because the effects of hpr 1 mutations on recombination are highly specific, increasing the rate of intrachromatid excision (Aguilera and Klein 1989; Klein 1995). Other classes of recombination, including simple gene conversion, and unequal sister chromatid exchange are unaffected by the hpr1 mutation. These data suggest that TRD in hpr1 strains is mediated through an increase in the rate of intrachromatid excision. In contrast, hpr 5 mutations, which increase multiple classes of gene conversion without affecting intrachromatid recombination (Aguilera and Klein 1989), have wild-type TRD rates (Table 1). The increase in TRD exhibited by hpr 1 null alleles is fully dependent on RAD52, but is independent of RAD1 (Ta- ble 1). Further evidence for the specificity of the hpr1 hyper-TRD phenotype is provided by the observation that other hyper-recombinational mutations, including top1 and top3, have no significant effect on TRD (data not shown; Christman et al. 1988; Wallis et al. 1989).

To corroborate the results of the genetic assay, we estimated rapid deletion frequencies independently through a physical analysis of telomere tract lengths (Fig. 4). Wild-type, hpr1, and hpr 1 rad1 cells, each containing an elongated $A D E 2$-marked telomere, were grown for $\sim 25$ generations on solid media, and telomere sizes were characterized (see Materials and methods). While wildtype cells display only low or undetectable levels of deleted forms after this limited growth, hpr1 and hpr1 rad1 cells exhibit a high frequency of deleted products. Up to $50 \%$ of the cells derived from a single colony contain deleted forms, suggesting the presence of single-division deletion events. A 10-fold increase in the rate of accumulation of deleted forms, relative to wild-type, was also estimated from continuous subculturing of hpr 1 cells in liquid media (see Fig. 6, below). Significantly, although there is no selection for tract length, the vast majority of deletion events restored tract sizes close to wild-type length. These data suggest that wild-type and hpr1-induced TRD pathways may share components.

Sir $3 p$ affects both the rate and spectrum of rapid deletion events

A number of proteins have been identified that are essential for telomeric silencing (Gilson and Gasser 1995). These include the silent information regulator (SIR) pro- 
Figure 3. Colony color reflects $A D E 2$ marked telomere tract size. (A) NdeI-digested DNAs from individual red colonies of $R A P 1$ cells (BL22-1c), carrying the elongated $A D E 2$-marked telomere (lanes 2-18), were treated as described in the legend to Fig. 1. (Lane 19, WTo) The original wild-type cells from which the single colonies in lanes 2-18 were derived. All of the VIIL telomeres remain elongated, although some deleted forms generated during growth are also observed. $(B)$ Ndel-digested DNAs from individual pure white colonies of wild-type RAP1 cells (BL22lc; lanes 2-17) were treated as in $A$. Lane $18\left(\mathrm{WT}_{\mathrm{o}}\right)$ refers to the original wild-type cells from which the single colonies in lanes 2-17 were derived. AJL275-2aVIIL-ADE (WT) was used as a control in lanes $1(A, B)$. The arrows in this and subsequent figures (Figs. 4-8) indicate the position of wild-type telomere length $(\sim 300$ bp).
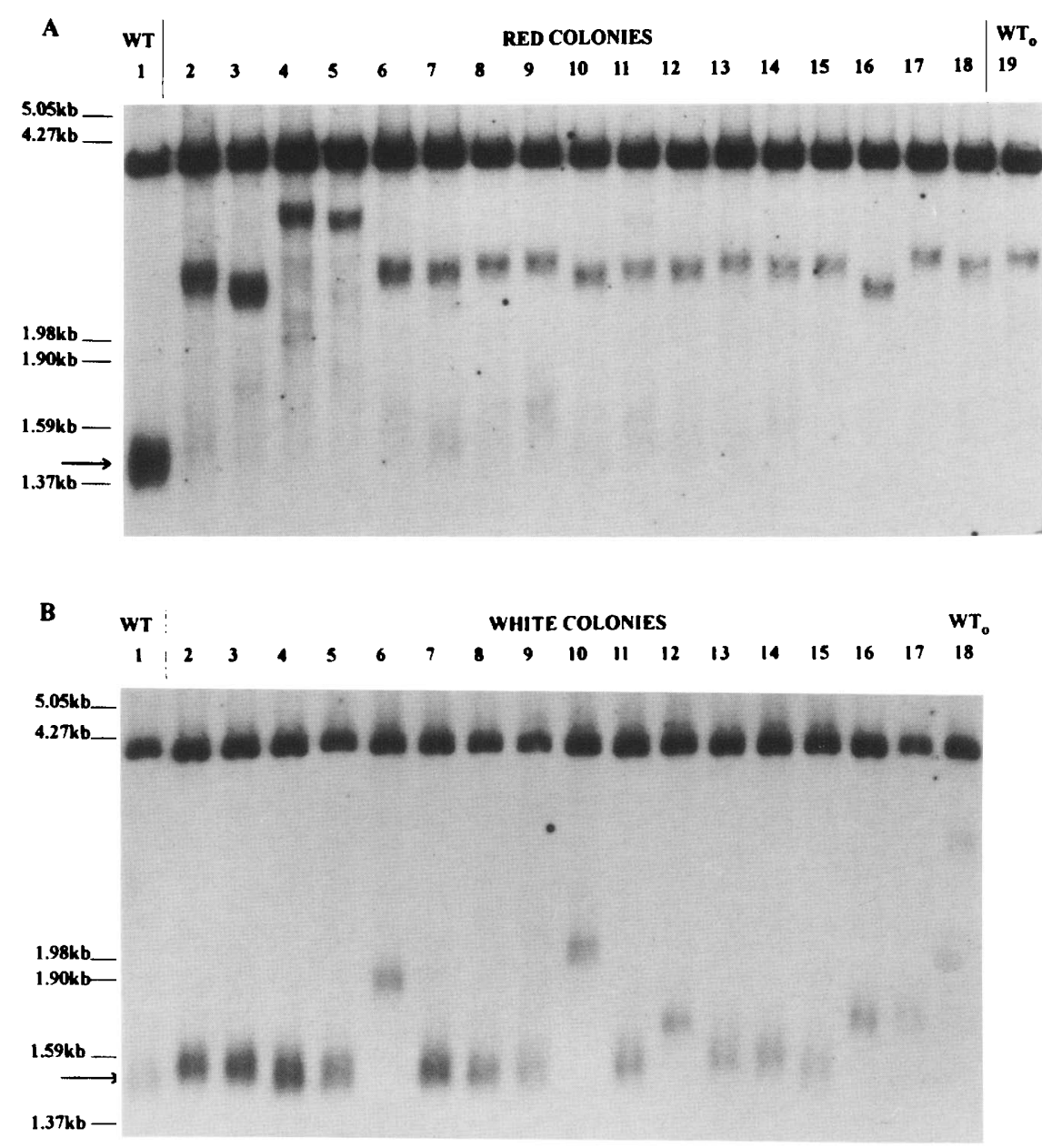

teins Sir2p, Sir3p and Sir $4 p$. Sir $3 p$ and Sir $4 p$ have the capacity to self-associate and associate with one another (Chien et al. 1991; Moretti et al. 1994), and appear to be recruited to the telomere by association with Raplp (Moretti et al. 1994; Cockell et al. 1995). These proteins are, therefore, candidates for factors involved in telosome structure or telosome/telosome associations among nonhomologs. To test whether these silencer proteins play a role in rapid deletion, we relied on physical assays, as sir mutations abolish the telomeric silencing required for the color assay. Because the physical assay is less sensitive than the genetic assay, we were restricted to testing for increases in the frequency or changes in the fidelity of TRD. We generated a set of strains containing the elongated $A D E 2$-marked telomere and either the sir2::URA3, sir $3:: L E U 2$, or sir4::URA3 disruption alleles. Neither the sir2 nor the sir4 null allele has a discernible effect on TRD (data not shown). In contrast, sir3 cells displayed an altered spectrum of rapidly shortened products. First, the majority of colonies $(27$ of 32 colonies tested in four independent experiments) displayed a clustering of slightly shortened fragments observed as a smear beneath the original telomeric fragment (Fig. 5). Such a population is never observed in wild-type cells, even after overexposure.
Second, out of the 13 discrete deletion products observed in the $32 \operatorname{sir} 3$ colonies tested, 10 shortened the elongated $A D E 2$-marked telomere by no more than $\sim 350$ bp. Only three telomeres returned to wild-type size. Interestingly, 4 of the 10 anomalously sized discrete products were present in equal abundance with the original telomeric fragment, suggesting a high frequency of firstdivision deletion events. The Sir3p-associating protein, Rad7p, involved in nucleotide excision repair (Paetkau et

Table 1. Rapid deletion is partially dependent on RAD52 and is stimulated by hprl mutations

\begin{tabular}{ll}
\hline Mutation & $\begin{array}{l}\text { Rate/cell division } \pm \text { S.D. } \\
\text { (no. fluctuation trials) }\end{array}$ \\
\hline wild type & $1.2 \times 10^{-3} \pm 0.34 \times 10^{-3}(10)$ \\
rad52 & $3.9 \times 10^{-4} \pm 2.3 \times 10^{-4}(6)^{\mathrm{a}}$ \\
rad1 & $3.8 \times 10^{-3} \pm 2.1 \times 10^{-3}(3)$ \\
hpr1 & $9.8 \times 10^{-3} \pm 4.0 \times 10^{-3}(7)^{\mathrm{a}}$ \\
hpr1 rad52 & $6.7 \times 10^{-4} \pm 0.11 \times 10^{-4}(4)$ \\
hpr1 rad1 & $1.6 \times 10^{-2} \pm 0.8 \times 10^{-2}(3)^{\mathrm{a}}$ \\
hpr5 & $1.2 \times 10^{-3} \pm 7.2 \times 10^{-5}(2)$ \\
\hline
\end{tabular}

avalue is different from wild type at $P<0.01$. (s.D.) Standard deviation. 


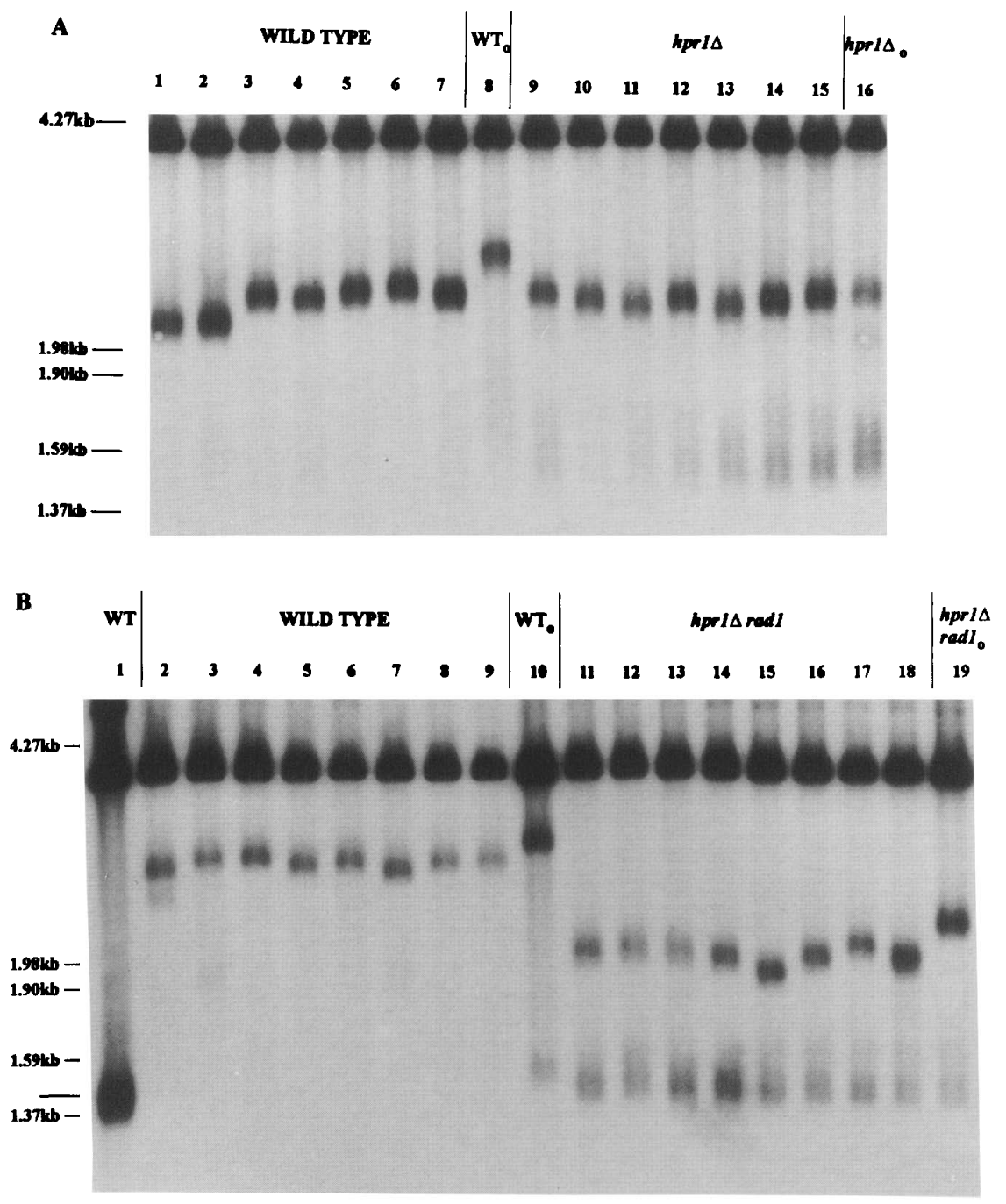

Figure 4. hpr1s alleles and hpr1s rad1 double mutants have elevated TRD rates. (A) DNA was isolated from single colonies of wild-type (BL22-2b; lanes 1-7) and hpr1 (BL33-4c; lanes 9-15) mutant cells, carrying the elongated $A D E 2$-marked telomere, after growth for $\sim 25$ generations, and subjected to Southern analysis as described in the legend to Fig. 1. (Lane 8, WT $_{0}$ ) The original wild-type cells used for the isolation of single colonies in lanes 1-7; (lane 16, hpr $1 \Delta_{\text {o }}$ ) the original hpr1 cells from which the single colonies in lanes 9-15 were derived. $(B)$ DNA was isolated from single colonies of wild-type (BL27-11a; lanes 2-9) and hpr1s rad1 (BL43-6d; lanes 11-18) cells and treated as in A. (Lane 10, $\left.\mathrm{WT}_{\mathrm{o}}\right)$ The original wild-type cells from which the single colonies shown in lanes 2-9 were derived; (lane 19, hpr1s rad1 0 ) the original hpr1s rad1 cells from which the single colonies (lanes 11-18) of hpr1A rad1 cells were derived. AJL275-2a-VIIL$\mathrm{ADE}$ (WT) was used as a control in lane 1 of $B$. al. 1994), had no effect on the rate $\left(1.2 \times 10^{-3} \pm 0.7 \times 10^{-3}\right.$ events/cell division) or fidelity (data not shown) of TRD.

Third, hpr 1 sir3 double mutants displayed a rate of deletion to wild-type tract length so high that the majority of double mutants contained deleted telomeres after only a few generations (data not shown). To study TRD in hpr1 sir3 double mutants over a shorter time scale, we conducted serial liquid subculturing and estimated the rate of accumulation of deleted forms in wildtype, hpr1 and hpr1 sir3 cells (Fig. 6). In this assay wildtype cells displayed a slow accumulation of deleted product $(\sim 0.2 \%$ /generation). hpr1 mutant cells showed a 10 fold increase in the initial rate of deletion over wild-type, reaching a maximum of $75 \%-80 \%$ deleted forms in 7 generations. hpr1 sir3 double mutants, on the other hand, reached this maximum at the earliest time point, precluding quantitative analysis, and additionally displayed the smear of fragments of smaller size than the original elongated telomere. Although a fraction of the double mutant cells remain elongated during the period of subculturing, further subculturing revealed that deletion in this population still occurs at rates equal to or greater than that present in hpr1 cells (data not shown). sir3 cells, therefore, appear to make the telomere more susceptible to processes acting rapidly to alter telomere size.

Rapid deletion is dependent on the telomeric $T G_{1-3}$ tract lengths of nonhomologs

The vast majority of TRD products are close to wild-type size in both wild-type and hpr1 cells. This observation could reflect a property of the marked telomere itself (e.g., a preferential site for recombination or endonucleolytic cleavagel, or the ability of the elongated $A D E 2$ marked telomere to measure length relative to telomeres of nonhomologous chromosomes. To differentiate between these two possibilities, we constructed a strain carrying a rap1::LEU2 null allele and a rap1-17 allele on a CEN plasmid (Fig. 7A), and subcultured the cells to elongate all telomeres. A plasmid shuffle was then carried out to replace the rap1-17 allele with a plasmidborne copy of wild-type RAP1. These cells were then subcultured for 30 generations, and the telomere sizes 


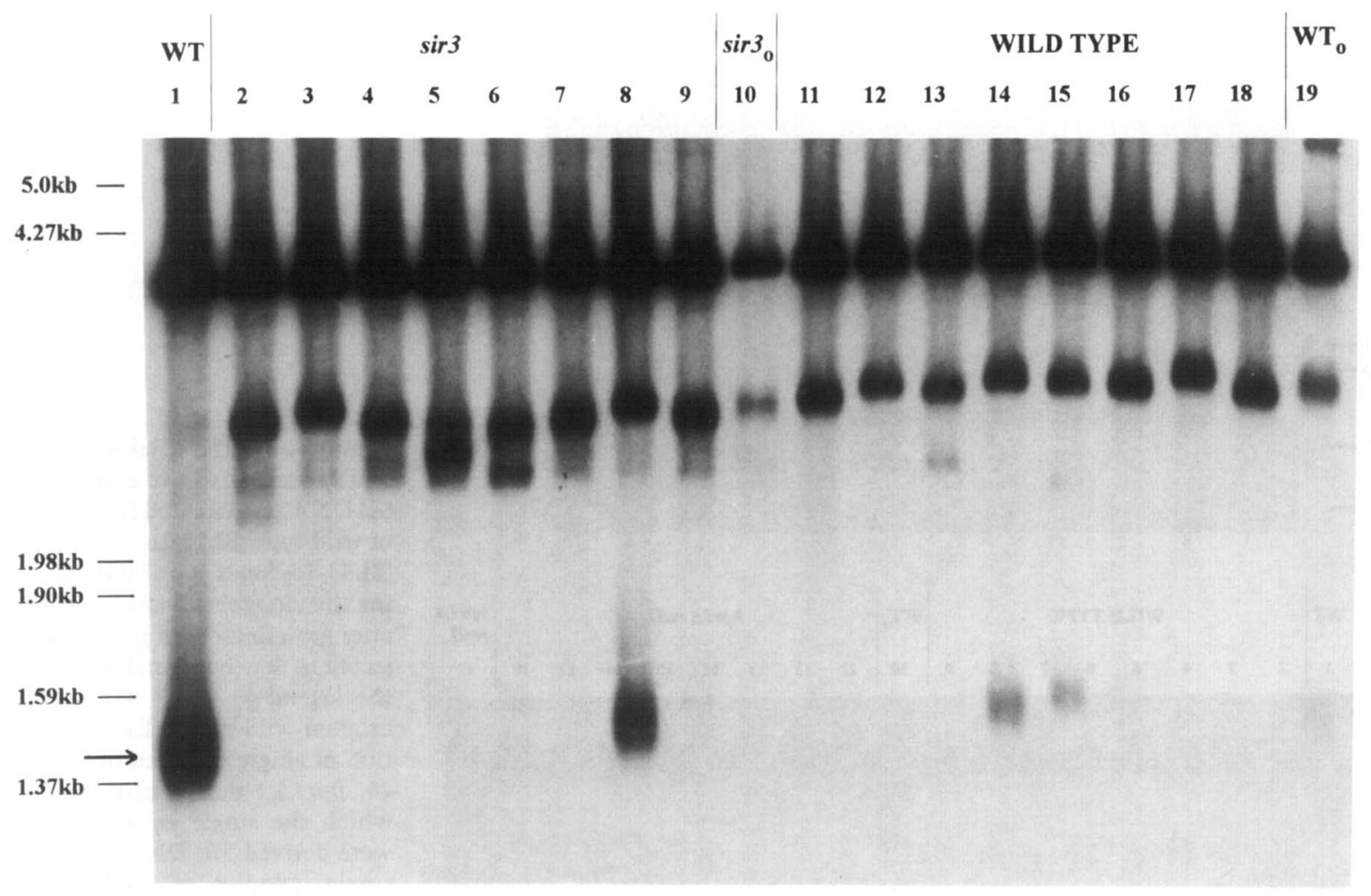

Figure 5. $\operatorname{sir} 3$ mutations alter the spectrum of rapid deletion events. DNA was isolated from individual colonies of wild-type (BL27-11a; lanes 11-18) and sir3::LEU2 (BL27-11a/sir3 transformant 5; lanes 2-9) cells carrying the elongated ADE2-marked telomere after $\sim 25$ generations of growth. DNA was treated as described in the legend to Fig. 1. (Lane 10, sir $3_{0}$ ) The original sir3 cells from which the single colonies shown in lanes 2-9 were derived; (lane 19, $\mathrm{WT}_{0}$ ) the original wild-type cells from which the single colonies shown in lanes 11-18 were derived. AJL275-2a-VIIL-ADE (WT) was used as a control in lane 1.

Figure 6. hpr1 $\Delta$ sir3 double mutants have more extreme effects on TRD than hpr1A and sir3 single mutants. Wild-type (BL271la), hpr1s (BL33-4c, left; BL33-17b, right), and hpr1s sir3 (BL33-4c/sir3 transformant 10 ) cells containing the elongated $A D E 2$-marked VIIL telomere were subcultured in YPAD liquid medium for three rounds, with each round representing two generations of growth. The number of subcultured generations are listed above each lane. DNA was isolated from each culture and subjected to Southern analysis as descirbed in the legend to Fig. 1. AJL2752a-VIIL-ADE (WT) is also shown.

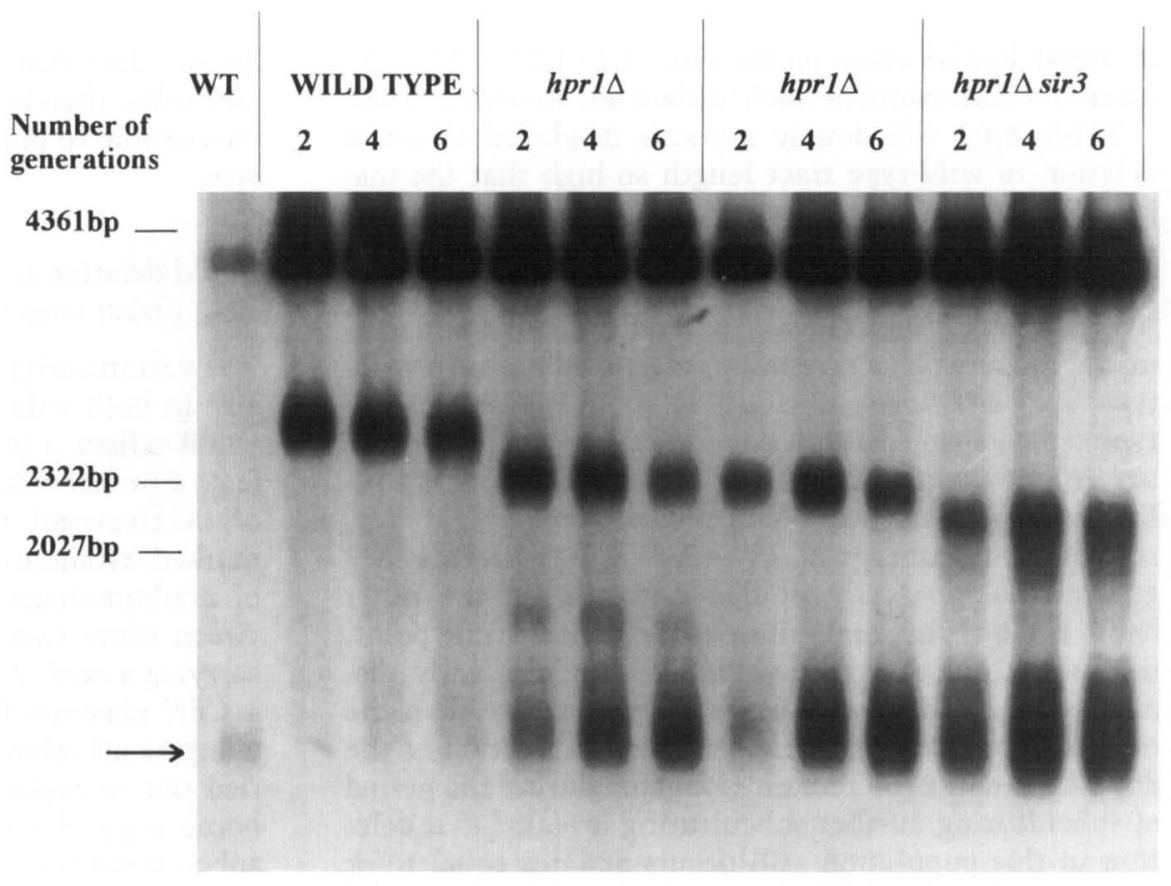



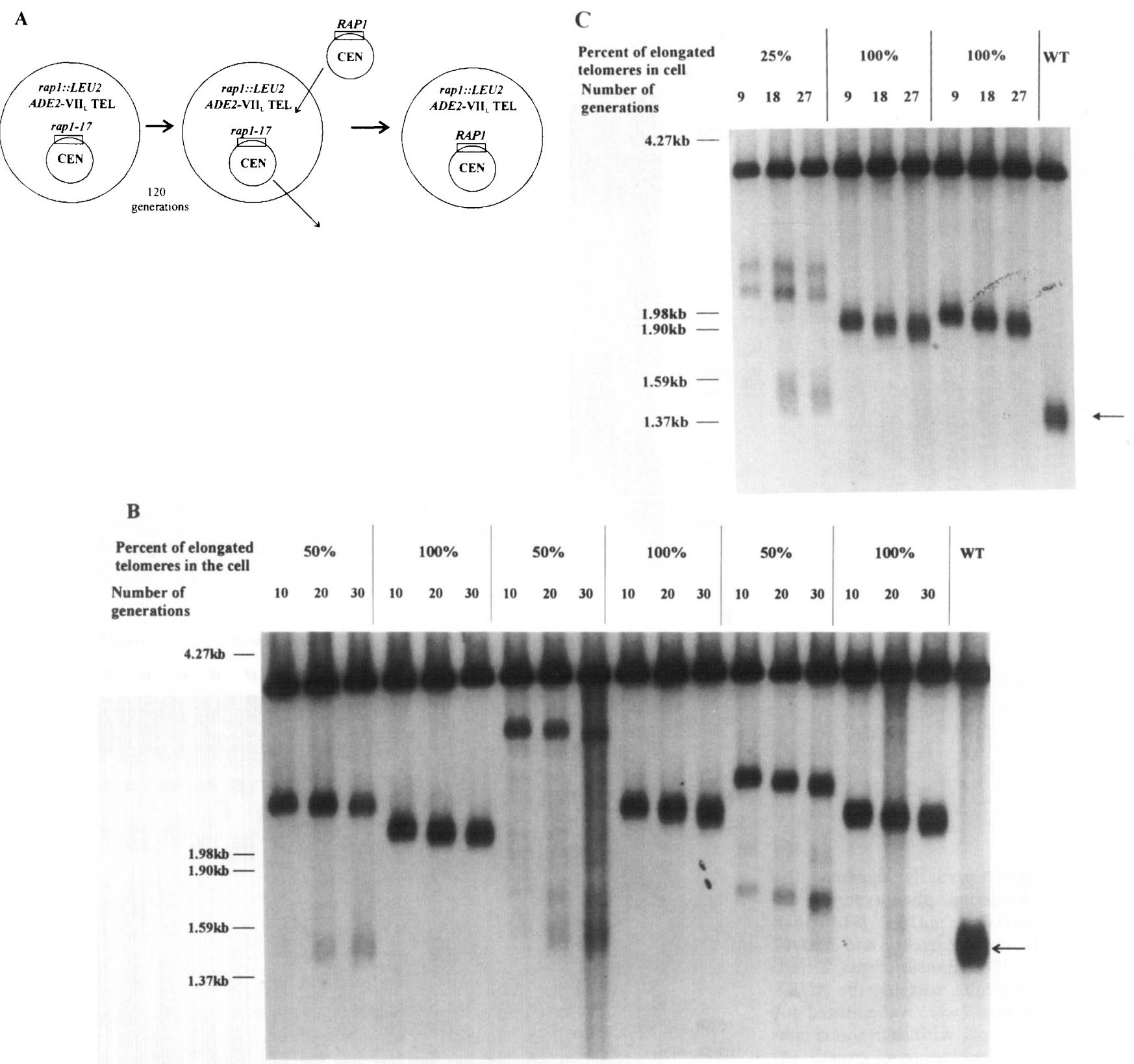

Figure 7. TRD is sensitive to the length of nonhomologous telomeres. (A) Diagram depicting a scheme to test the effect of nonhomologous telomere length (see text for details). $(B)$ Wild-type cells, containing all telomeres lengthened to varying extents (BL45-23c$\mathrm{P}+\mathrm{D}$ transformants 1,2 , and 4 from left to right; labeled $100 \%$ ), and wild-type cells, containing $50 \%$ elongated and $50 \%$ wild-type length telomeres (BL27-1 1a, BL27-11d, BL27-6a from left to right; labeled 50\%), each containing the elongated ADE2-marked telomere, were subcultured continuously in liquid media, with each round representing $\sim 10$ generations of growth. DNA was treated as described in the legend to Fig. 1. (C) hpr1 $\Delta$ cells containing $75 \%$ wild-type and $25 \%$ elongated telomeres (BL33-4c, generated through two backcrosses; see Materials and methods) and hpr1 $\Delta$ cells containing 100\% elongated telomeres (BL $45-23 \mathrm{c}-\mathrm{P}+\mathrm{D} / \mathrm{hprl}$ transformants 4 and $9 \mid$ were treated as in Fig. $7 \mathrm{~B}$. The doublet in the $25 \%$ lane is the presumed consequence of an aberrant deletion that arose prior to subculturing. Strain AJL275-2a-VIIL-ADE2 (WT) is also shown. There is no difference in the TRD rate of wild-type or hpr1 cells containing $25 \%$ or $50 \%$ elongated telomeres (data not shown).

were analyzed (see Materials and methods). Surprisingly, no deletion products were observed in wild-type RAP1 cells in which all telomeres were elongated to varying extents (Fig. 7B). hpr1 cells have a higher rate of TRD and, hence, increase the sensitivity of this assay. When we introduced the hpr1 mutation into the wild-type strain after global telomere elongation, however, no discrete deletion products were observed even after extensive subculturing (Fig. $7 \mathrm{C}$ ). These data indicate that rapid deletion is sensitive to the sizes of the telomeres of non- 
Figure 8. hpr $1 \Delta$ partially suppresses the telomere elongation phenotype of the rap1-17 mutation. rap1-17 [BL45-16aP (left) and BL45-23cP (right)] and rap1-17 hpr1s [BL45-29bP transformants 2 (left) and 10 (right) $]$ cells, carrying the $A D E 2$. marked telomere, were subcultured for four rounds (sl-s4), with each round consisting of $\sim 25$ generations of growth. $|A|$ DNA was isolated from each culture, and the $A D E 2$-marked telomere length assayed as described in the legend to Fig. 1. (WT) AJL275-2a-VIIL-ADE2. (B) The length of the majority of telomeres (the $\mathrm{Y}^{\prime}$ class telomeres) was assayed by Southern analysis of the same DNA as in $A$, with poly[d(GT)].poly[d(CA)] as a probe after digestion with XhoI. (WT) W303.
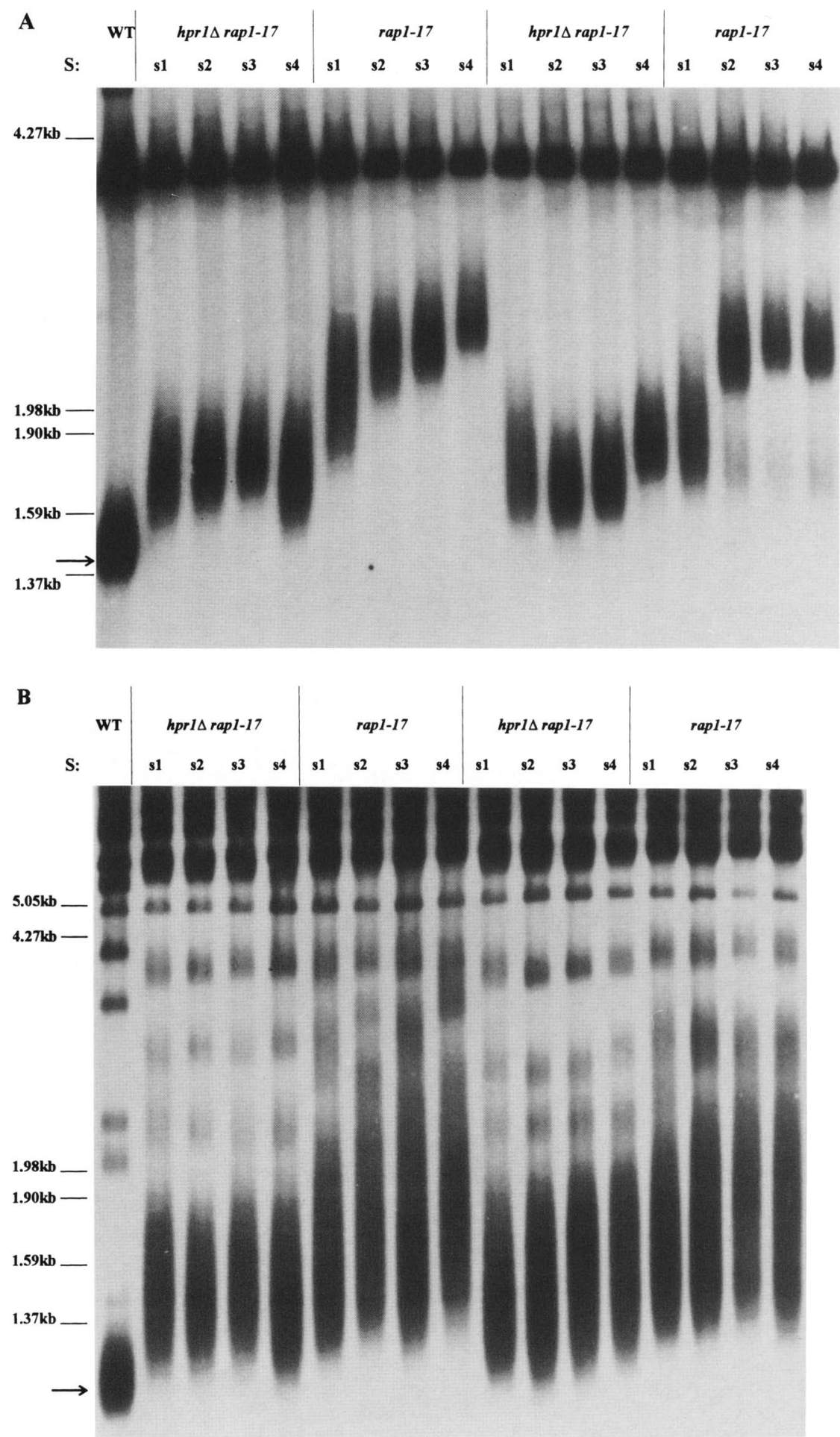

homologs and suggest that TRD may specify product size relative to the telomere lengths of other chromosomal termini. Consistent with this view, ADE2-marked elongated telomeres in tel1 cells display more extensive rapid deletions to sizes close to the expected tel1 telomere length [ $\sim 80$ bp (Lustig and Petes 1986); data not shown]. hprl suppresses the uncontrolled telomere elongation of rapl-17 cells

One explanation for the high rate of rapid deletion in rap1-17 cells is the presence of a telomere-size-control mechanism that acts on, or is induced by, the elongated telomeres. A prediction of this model is that elevating 
the rates of rapid deletion in hpr1 rap1-17 cells may alleviate telomere elongation by stimulating rapid deletion. To test this, we designed an assay in which telomere elongation by Rapl-17p could not take place before disruption of the HPR1 gene. We constructed a strain containing a rap1::LEU2 disruption, the wild-type copy of RAP1 on a CEN plasmid, and either an HPR 1 or an hpr 1::HIS3 disruption allele. All telomeres, including the ADE2-marked telomere, were of wild-type length. A plasmid shuffle was then used to replace the wild-type copy of RAP1 with the rap1-17 gene, and the strains were subcultured (see Materials and methods). Strains wildtype for HPR1 showed the expected elongation of both the ADE2-marked VIIL telomere and the majority of unmarked telomeres (Fig. 8A,B). In contrast, strains carrying the hpr1::HIS3 null allele displayed only partially elongated telomeres that had a less heterogeneous distribution.

\section{Discussion}

In this study we characterize a novel mechanism for telomere-size control that can process elongated yeast telomeres to wild-type tract lengths at high frequencies $\left(1.2 \times 10^{-3}\right.$ and $5.4 \times 10^{-3} /$ cell division in haploid and diploid cells, respectively). Because haploid cells have 32 telomeres, there is an $\sim 4 \%$ chance that in any cell division one of the telomeres may undergo rapid deletion. The chance of deletion is 10 -fold higher $(\sim 40 \%)$ in diploid cells, suggesting that the rate might be limited by the number of telomere pairing partners. These data suggest that TRD may play an active role in telomere size control, possibly by acting as a ruler for the maintenance of average telomere tract sizes. The unidirectionality of TRD to wild-type lengths may also be a mechanism to prohibit the formation of a new steady-state from telomeres of differing lengths.

Apart from the high fidelity of rapid deletion in wildtype cells, two additional factors suggest that the model system used in this study reflects events occurring in the wild-type state. First, rapid deletion events occur within the range of sizes observed in naturally occurring laboratory strains, which vary in average size from 150 to 800 bp. Second, the Raplp site density and the adherence to the telomeric consensus sequence is identical in wildtype and rap1-17 telomeres (data not shown).

\section{Potential mechanisms of TRD}

The evidence presented in this study suggests that the predominant TRD pathway involves intrachromatid recombination, although no single pathway is likely to explain all TRD events. Theoretically, several classes of processing events may explain rapid deletion. First, TRD may involve DNA slippage during replication. Although DNA polymerase slippage normally involves small (2-4 bp) deletions or expansions of repeated sequences, a multiplicity of such events or an aberrant event might result in the deleted product. However, mutations in the mismatch repair genes (i.e., PMS1, MSH2, MSH3) and in
$R T H 1$, encoding a $5^{\prime} \rightarrow 3^{\prime}$ exonuclease, all of which stimulate DNA polymerase slippage (Strand et al. 1993, 1995; Johnson et al. 1995), have no corresponding effect on TRD. Similarly, elimination of $R A D 5$, encoding a helicase thought to be involved in DNA polymerase slippage (Johnson et al. 1995), does not inhibit rapid deletion.

Second, telomeres may undergo unequal sister chromatid exchange (USCE) or, alternatively, ectopic exchange or gene conversion between the telomeres of nonhomologs. In the former case, physical assays should display an elongation of the $A D E 2$-marked telomere associated with each rapid deletion event. Such elongation, however, is never found in either wild-type or rap1-17 cells. Ectopic events are also rendered unlikely by the rarity of rapid elongation events in which elongated or wild-type-length marked telomeres are the recipient of additional telomeric tracts. Similarly, the hpr5 mutation, which increases the frequency of many classes of sister chromatid and ectopic gene conversion (Aguilera and Klein 1989|, has no effect on rapid deletion.

Third, telomeres may be processed by an endonuclease. This mechanism seems unlikely to be the major pathway because (1) the majority of TRD events are dependent on the RAD52 gene, and (2) the hpr1 enhancement of TRD is fully RAD52-dependent. The nuclease activities associated with telomerase (Greider 1995; Melek et al. 1996) are also unlikely to contribute to TRD because a null allele of TLC1, encoding the RNA component of telomerase, has no effect on TRD. Similarly, mutations in two other genes encoding telomere-sizing factors, TEL1 (Lustig and Petes 1986) and EST1 (Lundblad and Szostak 1989|, do not significantly influence TRD rate.

Fourth, telomeres may shorten via an intrachromatid recombination pathway. Two considerations favor this interpretation. First, an intrachromatid event most simply explains the lack of a stable reciprocal product. Second, the characteristics of recombination in hpr1 cells also favor intrachromatid excision. hpr1 mutations specifically increase the frequency of intrachromatid excision between repeated elements in a RAD52-dependent fashion, as observed for rapid deletion (Klein 1995). This $R A D 52$-dependence also argues against the possibility that TRD is influenced by the reported transcriptional activation function of Hprlp (Zhu et al. 1995). In wildtype cells, Hprlp may repress TRD intrachromatid recombination by restricting access of recombinational enzymes or by promoting the repair of recombinogenic lesions.

To what extent do events in the hpr 1 hyper-recombination mutant reflect the mechanism of TRD in wildtype cells? Several novel characteristics of the recombinant product argue for a mechanistic similarity. First, the product of the reaction in wild-type and hpr 1 cells is identical. An increase in the efficiency of a second independent pathway acting on reiterated imperfect telomeric repeats would be unlikely to yield the same wildtype length product. Second, as for wild type, the deleted product does not appear to proceed through any apparent reproducible (or long-lived) intermediate. Third, elonga- 
tion of the majority of cellular telomeres eliminates rapid deletion in both wild-type and hpr1 cells. Fourth, unlike most hpr1-induced events (Santos-Rosa and Aguilera 1994), TRD in both wild-type and hpr 1 cells is RAD1-independent. Hence, the same type of novel RAD52-dependent sizing mechanism may be operating in both wild-type and hpr1 cells, arguing for at least a partial mechanistic similarity. We note that our inability to observe an effect of rad52 mutations in rap1-17 cells in a previous study (Kyrion et al. 1992) may be the result of the insensitivity of the physical assays used in that study.

Among the classes of potential intrachromatid TRD events are single-strand annealing (SSA), reciprocal crossing-over, and abortive crossing-over. SSA involves DNA breakage, strand recision, reannealing, elimination of the $3^{\prime}$ overhang by the $\mathrm{Radlp} / \mathrm{Rad} 10 \mathrm{p}$ endonuclease (when repeats are separated by nonhomology), and ligation. The ultimate consequence is the loss of the intervening sequences (Tomkinson et al. 1993). Because telomeres consist of imperfect $\mathrm{TG}_{1-3}$ repeats, Radlp-independent TRD can take place by SSA only if pairing does not produce a $3^{\prime}$ overhang and if mismatches between imperfectly paired sequences are tolerated. The alternative possibilities are reciprocal and abortive crossovers (Haber 1992) between irregular repeats that should proceed through the formation of heteroduplex DNA. The DNA damage that initiates TRD remains unknown. It is intriguing to speculate, however, that $\mathrm{Cdcl} 3 \mathrm{p}$, which appears to be required for the repair of single-stranded telomeric damage (Garvik et al. 1995), may regulate the initiation of TRD.

\section{The role of Sir $3 p$ in telomeric recombination}

One unexpected finding is that the Sir $3 p$ influences a number of processes acting rapidly at the telomere. sir 3 mutant cells display a heterogeneous set of fragments extending to sizes $\sim 350 \mathrm{bp}$ smaller than the original elongated telomere and a high frequency of abnormally deleted telomeric species. In addition, mutations in SIR3 result in an increase in the rate of hpr 1 -induced rapid deletion. Neither sir2 nor sir4 null alleles confer these phenotypes. This may reflect a lack of involvement of Sir $2 p$ and Sir $4 p$ in TRD, or, alternatively, a requirement for these proteins not detectable by physical assays. We note that the sir3::LEU2 disruption allele used in these studies displays residual activity under some conditions (see Materials and methods). Thus, a sir 3 null allele may have a more extreme or altered rapid deletion phenotype.

The nucleotide excision repair protein, $\operatorname{Rad} 7 \mathrm{p}$, repairs UV-induced DNA damage preferentially from silent loci and nontranscribed strands (Verhage et al. 1994). Genetic and two-hybrid data suggest that $\operatorname{Sir} 3 p / \operatorname{Rad} 7 p$ interaction may be required for Rad7p to gain access to silent domains (Paetkau et al. 1994). However, no significant difference in TRD rates or fidelity were observed in $\mathrm{rad} 7$ null alleles (data not shown). Thus, the effect of Sir3p on rapid deletion is mechanistically distinct from the action of $\operatorname{Rad} 7 p$ and Sir3p in DNA repair.
One possibility is that Sir3p restricts access of a number of distinct telomeric rapid degradation processes (e.g., exonucleolytic and recombinational pathways). A second possibility is that the sir 3 phenotypes are different manifestations of the same rapid deletion process. For example, the smear observed in sir 3 cells may be the result of the promiscuous action of an exonuclease involved in TRD or of the accumulation of a multiplicity of aberrantly deleted products. These species may also represent intermediates normally processed more efficiently in wild-type cells. In both sets of models, the action of Sir3p may be mediated through either the structure of the telosome or telosome/telosome interactions (Fig. 9).

Both possibilities are consistent with the ability of Sir3p to be recruited to the telomere by Raplp and to self-associate (Moretti et al. 1994; Cockell et al. 1995; Lustig et al. 1996). It is interesting that an alteration in TRD precision is also found in cells containing Rapl$17 p$, which lacks the Raplp carboxy-terminal 165amino-acid domain necessary for Raplp/Sir3p association (Kyrion et al. 1992; Moretti et al. 1994).

The analysis of deletion kinetics suggests the presence of two populations that differ in TRD rate in hpr 1 cells. In hpr 1 sir 3 alleles, $\sim 80 \%$ of elongated telomeres are deleted in a few generations. The remaining $20 \%$ seems more stable, although they still exhibit a TRD rate elevated relative to wild-type and $h p r 1$ cells. This may reflect a subclass of telomeres impaired in their ability to align with other telomeres (possibly through an alteration in telomeric sequence or telosome structure on one of the interacting chromatids|. Alternatively, this distribution may reflect an epigenetic effect in which telomeres switch between recombinationally proficient and nonproficient telosome states.

\section{Intertelomeric associations and TRD}

Paradoxically, although TRD is likely to be mediated through an intrachromatid pathway, the specificity of the process appears to be governed by the telomere lengths of nonhomologs. These data suggest that associations between telomeres play a role in determining the fidelity of rapid deletion. Such telomeric interactions have been observed in a multiplicity of organisms including yeast (Klein et al. 1992; Dernberg et al. 1995). An alternative possibility is that the higher abundance of telomeres titrates a limiting factor necessary for rapid deletion. This second possibility is unlikely for two reasons. First, wild-type and hpr 1 spore colonies containing on average either $50 \%$ or $25 \%$ of telomeres elongated (with the rest wild type in length) do not display differences in TRD frequency (data not shown). Second, rap117 cells, which produce extremely elongated telomeres, are highly proficient in rapid deletion (Kyrion et al. 1992).

We propose a model in which alignment of telosomes precedes rapid deletion (Fig. 9). The nature of the tract alignment or synapsis may then determine the regions of the tract that are susceptible to rapid deletion. If telo- 


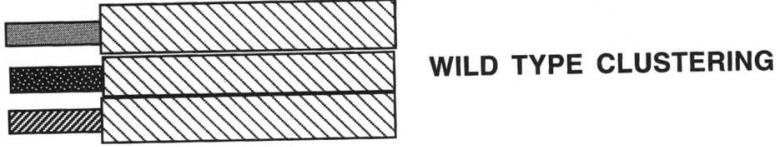

ABERRANT CLUSTERING

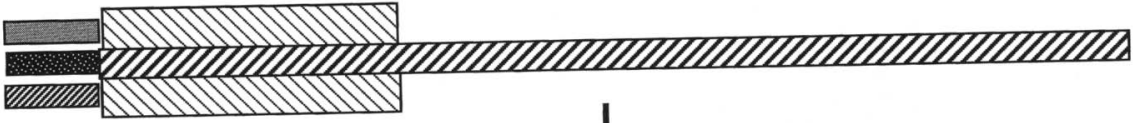

INTRACHROMATID
RECOMBINATION

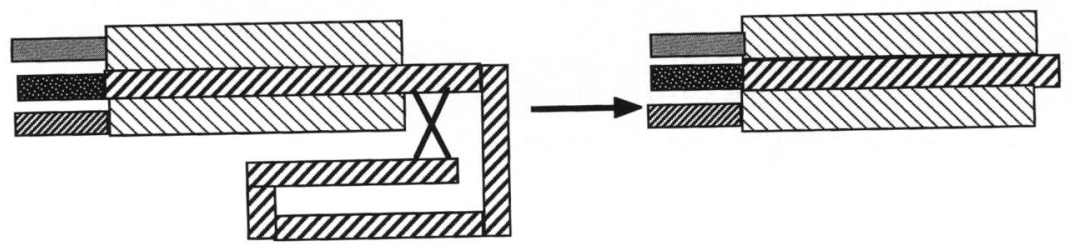

Figure 9. A speculative model for rapid deletion in yeast. We propose that TRD is a two-stage process. In the first stage, telosomes / shown by the light and dark hatched boxes for wild-type and elongated telomeres, respectively) align at the nucleosomal-telosomal boundary and cluster through associations between telosomal proteins (e.g., Sir3p) of heterologous telomeres. This clustering may afford protection against recombinational and nucleolytic enzymes. Telomeres that elongate beyond wild type would not be included in such a cluster and hence not be stabilized by telosomal associations. In the second stage, the intrachromatid excision machinery carries out the deletion event in these telomeres. The recombination event is drawn here as a simple crossover. However, the event may also proceed either by a RADlp-independent SSA pathway or by a double-strand-break-mediated single-strand invasion (i.e., an abortive crossover). These latter two classes may be promoted by invasion of the terminal $3^{\prime}$ overhang at the chromosomal terminus into sequences adjacent to the clustered telomeres. meres align at the nucleosome-telosome junction, pairing may extend through the region of wild-type-length telomeres. Conceivably, unpaired elongated telomeres (e.g., the elongated $A D E 2-$ marked telomere) may be more susceptible to TRD events. Our data raise the possibility that Sir3p may be involved in this alignment. It is unlikely that Sir3p is the only component governing fidelity, however, because sir 3 cells can form deleted products of wild-type length. We envision that TRD normally acts on substrates of smaller sizes than those in our model system to prevent the slow accumulation of deleterious elongated telomeres that may be generated by telomerase or secondary recombinational pathways. TRD is unlikely to be the only mechanism of size control, however, because elongated, but not wild-typelength, telomeres, also slowly shorten in size over multiple generations in wild-type cells /see Figs. 1B and $7 \mathrm{~B}, \mathrm{C})$. Regardless, TRD is likely to be an important component of the cellular mechanism that regulates average telomere tract size and heterogeneity in yeast.

\section{Implications for telomere size regulation in other organisms}

As similar deletion events have been reported in ciliates, trypanosomes, yeast, and humans, the process underlying rapid deletion may be common to eukaryotes. Telomere size in yeast and other eukaryotes may be governed by both TRD and the activity and processivity of telomerase. Because rapid deletion appears to be regulated through the association among telomeres and global telomere length, the activity of telomerase alone would not be the sole predictor of telomere size in cells containing telomeres of different sizes. TRD is also a potential player in the telomere shortening observed in senescing cells, as TRD would be expected to accelerate the process of stochastic telomere loss.

TRD-like events have been observed in individual telomeres of human immortalized cell lines. These aberrant deletions, similar to those found in the yeast rap117 allele, may result in chromosome instability (Murnane et al. 1994). The increased heterogeneity observed in a recently described immortalized cell line lacking telomerase may also be caused by a similar aberrant regulation of telomere size (Bryan et al. 1995). These intriguing findings raise the possibility that aberrant TRD may contribute to the generation of clonal cell types bearing chromosome rearrangements, associated with a wide variety of disease states.

The studies described here have allowed us to gain insights into the mechanism of rapid deletion and its possible role in telomere size control in yeast. Further investigation of these events will help to determine the types of activities that act at the telomere and the factors that regulate telomere size in both yeast and higher eukaryotes.

\section{Materials and methods}

Plasmids

The plasmids used in this study are described in Table 2.

Yeast strains and methods

Yeast strains used in this study were isogenic to W303 and are 
listed in Table 3. Strains were generated by standard crosses of wild-type strains with rap1-17 strains containing an elongated $A D E 2$-marked telomere or, when noted, by plasmid shuffles. Standard crosses or, alternatively one- or two-step gene disruptions (Kaiser et al. 1994), with the plasmids listed in Table 2, were utilized to generate the various mutant strains. Spores for shuffled strains) carrying the appropriate mutation and the elongated $A D E 2$-marked telomere were recovered after sporulation (or shuffling). Strains singly backcrossed (i.e., AJL412, BL22, BL27 spore colonies) contain an average of $50 \%$ elongated telomeres. Strains proceeding through two backcrosses (i.e., BL29BL33 spore colonies) had an average of $25 \%$ elongated telomeres. In both wild-type and hpr1 strains, no differences were observed in TRD rate between cells containing $25 \%$ and $50 \%$ elongated telomeres. We note that the sir $3:: L E U 2$ allele used in this study has been demonstrated to retain some minimal amino-terminal function, because overproduction of Sirlp suppresses this allele, but not a sir3 null allele (Stone et al. 1991).

A plasmid shuffle (Kaiser et al. 1994) was used to generate the strains required to determine the telomere phenotype in $h p r 1$ rap1-17 cells. YDS/D130 carrying the chromosomal rap $1:: L E U 2$ and the RAP1 gene on $\mathrm{pD} 130$ was crossed with AIL437-1d, that has a ura3-ADE2-marked VIIL telomere of normal length (Liu et al. 1994), forming BL41. BL41-3b carries the rap1::LEU2 allele at its chromosomal locus, RAP1 on the pD130 plasmid, and the ura3-ADE2-marked VIIL telomere. BL45 was generated by crossing BL4l-3b with UF68-1C. BL4529b carries hpr $1:: H I S 3$, rap $1:: L E U 2$, pD130, and the ura3$A D E 2$-marked VIIL telomere. A plasmid shuffle was performed to replace pDl30 with pRS316/rapl-17 in strains BL45-29b, BL45-16a, and BL45-23c /the latter two carrying a wild-type copy of $\mathrm{Hprlp}$ ) to give rise to strains BL45-29bP, BL45-16aP, and $\mathrm{BL} 45-23 \mathrm{cP}$. These strains are isogenic except for the differences in the presence or absence of Hprlp. All three strains were subcultured for four rounds with each round representing $\sim 25$ generations of cell growth.

To determine whether TRD at the ADE2-marked telomere is sensitive to telomere lengths of nonhomologs in both wild-type and hpr 1 cells, another plasmid shuffle was carried out on strain BL45-23cP, containing the rap1-17 allele, after four rounds of subculturing. In this strain, which contained $100 \%$ of telomeres elongated to varying extents, pRS316/rapl-17 was replaced with $\mathrm{pD} 130$ to give rise to strain $\mathrm{BL} 45-23 \mathrm{c}-\mathrm{P}+\mathrm{D}$. The HPR1 gene in $\mathrm{BL} 45-23 \mathrm{c}-\mathrm{P}+\mathrm{D}$ was disrupted by $\mathrm{pABx} 4$ to give rise to strain BL45-23c-P +D/hprl $\Delta$

To construct strains in which the elongated $A D E 2$-marked telomere was replaced with a wild-type-length URA3-marked telomere, Sall/EcoRI-digested pURA3-VIIL /Gottschling et al. 1990) was transformed into BL27-11a, which carries $\sim 50 \%$ elongated and $\sim 50 \%$ wild-type-length telomeres, including an elongated ura3-ADE2-marked VIIL telomere (Liu et al. 1994). $\mathrm{Ura}^{+} \mathrm{Ade}^{-}$transformants were selected, and Southern analysis was used to confirm that the ADE2-marked telomere was replaced with a URA3-marked VIIL telomere of wild-type length. The transformants were subcultured for four rounds with each round representing $\sim 25$ generations of growth.

For each strain construction, the presence and length of an ADE2-marked telomere, URA3-marked telomere, or the overall length of $\mathrm{Y}^{\prime}$ class telomeres was determined as described previously (Kyrion et al. 1993). The length of the ADE2-marked VIIL telomere for each strain is listed in Table 3.

\section{Assays for rapid deletion}

Color assay TRD rates in most strains was determined by use of the color assay. For each fluctuation assay, 7-10 single colonies of size $\sim 1 \mathrm{~mm}$ were picked from YPAD plates and resuspended in $300 \mu \mathrm{l} \mathrm{H}_{2} \mathrm{O}$. Cells were diluted and $\sim 1000$ cells were plated on limiting adenine media (Kyrion et al. 1993). After $\sim 3$ days of incubation at $30^{\circ} \mathrm{C}$, cells were incubated at room temperature for an additional 3-5 days for full color development. Red colonies, white colonies, and white colonies with red sectors were scored. In each mutant strain, DNA was isolated from a subset of both white colonies with red sectors and pure white colonies to determine telomere sizes, and the percentage of colonies containing deleted telomeres was applied to the whole population. We note that rad52 rad1 double mutants could not be analyzed for TRD rate becuase of an alteration in pigment accumulation that obscures the color assay. However, physical assays did not reveal any increase in the rate of TRD in these cells.

\section{Physical assays Two physical assays were used:}

1. Solid media subculturing for detecting clonal deletion Wild-type and mutant cells were dispersed on YPAD media and eight to nine single colonies of identical size (1.5-2.0

Table 2. Plasmid constructs

\begin{tabular}{lll}
\hline Plasmid & Relevant gene & Reference \\
\hline pES28 & sir2::URA3 & Chien et al. (1993) \\
pD330 & sir3::LEU2 & Shore et al. (1984) \\
pCDC77 & sir4::URA3 & Chien et al. (1993) \\
pDG759 & rad7::LEU2 & Paetkau et al. (1994) \\
pSH87 & rad5::URA3 & Johnson et al. (1992) \\
pJH523 & pms1 $::$ URA3::pms14 & Strand et al. (1993) \\
pABx4 & hpr1 $33:: H I S 3$ & Aguilera and Klein (1990) \\
pMSH2::Tn10luk & msh2::Tn10luk & Reenan and Kolodner (1992) \\
pMSH3::LEU2 & msh3::LEU2 & Selva et al. (1995) \\
pR2.10 & rth1::URA3 & Johnson et al. (1995) \\
pBlue61::LEU2 & tlc1::LEU2 & Singer and Gottschling (1994) \\
pPG47 & tel1::URA3 & Greenwell et al. (1995) \\
pVL140 & est1::URA3 & Lundblad and Szostak (1989) \\
pD130 & RAP1/CEN & Kurtz and Shore (1991) \\
pRS316/rap1-17 & rap1-17/CEN & Kyrion et al. (1992) \\
pURA-VIIL-TEL & adh4-URA3-TEL & Gottschling et al. (1990) \\
\hline
\end{tabular}


Table 3. Yeast strains

\begin{tabular}{|c|c|c|}
\hline Strain & Genotype & $\begin{array}{l}\text { ADE2-marked } \\
\text { telomere size }\end{array}$ \\
\hline W303a $a^{a}$ & MATa leu2-3,112 HIS3 ade2-1 trp1-1 ura3-1 & N.A. \\
\hline $\mathrm{W} 303 \alpha^{\mathrm{a}}$ & MATa leu2-3,112 his3-11,15 ade2-1 trp1-1 ura3-1 & N.A. \\
\hline YDS/D130 & MAT $\alpha$ rap1::LEU2 leu2-3,112 trp1 his3 ade2-1 ura3-1 pD130/RAP1 & N.A. \\
\hline $\mathrm{FP} 300 \alpha^{\mathrm{c}}$ & MAT $\alpha$ srs2AHIS3 (hpr5-59) leu2-3,112 his3-11,15 ade2-1 trp1-1 ura3-1 & N.A. \\
\hline $\mathrm{W} 814-29 \mathrm{a}^{\mathrm{a}}$ & MAT $\alpha$ top1-8 (top 1::LEU2) leu2-3,112 his3-11,15 ade2-1 trp1-1 ura3-1 & N.A. \\
\hline W839-9 $\mathrm{a}^{\mathrm{a}}$ & $\begin{array}{l}\text { MATa rad52-8 (rad52::TRP1) rad1::LEU2 leu2-3,112 his3-11,15 ade2-1 } \\
\text { trp1-1 ura3-1 }\end{array}$ & N.A. \\
\hline W839-5c $c^{a}$ & MATa rad52-8 (rad52::TRP1) leu2-3,112 his3-11,15 ade2-1 trp1-1 ura3-1 & N.A. \\
\hline W839-6 $b^{a}$ & MATa rad1::LEU2 leu2-3,112 his3-11,15 ade2-1 trp1-1 ura3-1 & N.A. \\
\hline W878-1 $\mathrm{c}^{\mathrm{a}}$ & MATa top3-3 (top3::LEU2) leu2-3,112 his3-11,15 ade2-1 trp1-1 ura3-1 & N.A. \\
\hline UF $68-1 c, 4 c^{c}$ & $\begin{array}{l}\text { MATa (MATa for 4c) hpr1 } 33 \text { (hpr1::HIS3) leu2-3,112 his3-11,15 ade2-1 } \\
\quad \text { trp1-1 ura3-1 }\end{array}$ & N.A. \\
\hline AJL275-2a-VIIL-ADE ${ }^{\mathrm{d}}$ & MATa leu2-3,112 his3-11,15 ade2-1 trp1-1 ura3-1 URA3-ADE2-VIIL & $300 \mathrm{bp}$ \\
\hline AJL $437-1 d$ & $\begin{array}{l}\text { MATa leu2-3,112 HIS3 ade2-1 trp1-1 ura3 } 31:: T R P 1:: \text { ura3 } 31 \\
\quad \text { ura3-ADE2-VIIL }\end{array}$ & $300 \mathrm{bp}$ \\
\hline AJL $394-1 \mathrm{~d}^{\mathrm{e}}$ & $\begin{array}{l}\text { MAT } \alpha \text { leu2-3,112 his3-11,15 ade2-1 trp1-1 ura3-1 rap1-17 } \\
\text { URA3-ADE2-VIIL }\end{array}$ & N.T. \\
\hline AJL $442-4 b^{e}$ & MAT $\mathrm{l}$ leu2-3,112 HIS3 ade2-1 trp1-1 ura3-1 rap1-17 ura3-ADE2-VIIL & N.T. \\
\hline AJL $441-2 b^{e}$ & $\begin{array}{l}\text { MATa leu2-3,112 his3-11,15 ade2-1 trp1-1 ura3-1 rap1-17 } \\
\text { ura3-ADE2-VIIL }\end{array}$ & N.T. \\
\hline AJL412-4d & MATa leu2-3,112 his3-11,15 ade2-1 trp1-1 URA3-ADE2-VIIL & 840 bp \\
\hline AJL412-2c & MATa leu2-3,112 HIS3 ade2-1 trp1-1 ura3-1 URA3-ADE2-VIIL & $950 \mathrm{bp}$ \\
\hline $\mathrm{BL} 22 \cdot 1 \mathrm{c}, 2 \mathrm{~b}, 3 \mathrm{c}, 4 \mathrm{~b}$ & $\begin{array}{l}\text { MATa (MATa for } 3 \mathrm{c} \text { and } 4 \mathrm{~b}) \text { leu2-3,112 his3-11,15 ade2-1 trp1-1 ura3-1 } \\
\text { URA3-ADE2-VIIL }\end{array}$ & $1800-2000 \mathrm{bp}$ \\
\hline BL27-11a & MATa leu2-3,112 his3-11,15 ade2-1 trp1-1 ura3-1 ura3-ADE2-VIIL & $2100 \mathrm{bp}$ \\
\hline $\mathrm{BL} 32 \cdot 7 \mathrm{a}$ & MATa leu2-3,112 his3-11,15 ade2-1 trp1-1 ura3-1 URA3-ADE2-VIIL & $1400 \mathrm{bp}$ \\
\hline BL32-7b & MAT $\alpha$ leu2-3,112 HIS3 ade2-1 trp1-1 ura3-1 URA3-ADE2-VIIL & $1400 \mathrm{bp}$ \\
\hline BL29-12b,14b & $\begin{array}{l}\text { MAT } \alpha \text { (MATa for 14b) hpr5::HIS3 leu2-3,112 his3-11,15 ade2-1 trp1-1 } \\
\quad \text { ura3-1 URA3-ADE2-VIIL }\end{array}$ & $1650-1700 \mathrm{bp}$ \\
\hline BL30-6c, $12 b$ & $\begin{array}{l}\text { MAT Top t::LEU2 leu2-3,112 his3-11,15 ade2-1 trp1-1 ura3-1 } \\
\quad \text { URA3-ADE2-VIIL }\end{array}$ & $1550 \mathrm{bp}$ \\
\hline BL31-2a, 17c & $\begin{array}{l}\text { MAT } \alpha \text { (MATa for } 17 \mathrm{c}) \text { rad1::LEU2 leu2-3,112 his3-11,15 ade2-1 trp1-1 } \\
\quad \text { ura3-1 URA3-ADE2-VIIL }\end{array}$ & $1400-1700 \mathrm{bp}$ \\
\hline BL31-2c,6a, 14a & $\begin{array}{l}\text { MATa rad52::TRP1 leu2-3,112 his3-11,15 ade2-1 trp1-1 ura3-1 } \\
\text { URA3-ADE2-VIIL }\end{array}$ & $1400-1600 \mathrm{bp}$ \\
\hline BL34-8c, $11 \mathrm{c}$ & $\begin{array}{l}\text { MATa }(\text { MAT } \alpha \text { for } 11 \mathrm{c}) \text { top3::LEU2 leu2-3,112 his3-11,15 ade2-1 trp1-1 } \\
\quad \text { ura3-1 URA3-ADE2-VIIL }\end{array}$ & $1600-1700 \mathrm{bp}$ \\
\hline BL33-4c, $17 b$ & $\begin{array}{l}\text { MATa }(\text { MAT } \alpha \text { for } 17 \mathrm{~b}) \text { hpr } 1:: \text { HIS3 leu2-3,112 his3-11,15 ade2-1 trp1-1 } \\
\quad \text { ura3-1 URA3-ADE2-VIIL }\end{array}$ & $1440 \mathrm{bp}$ \\
\hline BL36-1c, 8c & $\begin{array}{l}\text { MAT } \alpha \text { hpr1::HIS3 rad52::TRP1 rad1::LEU2 rap1-17 leu2-3,112 } \\
\text { his3-11,15 ade2-1 trp1-1 ura3-1 }\end{array}$ & N.A. \\
\hline BL40-12d, BL43-6d, $12 b$ & $\begin{array}{l}\text { MAT }(\text { MATa for 6d) hpr1::HIS3 rad1::LEU2 leu2-3,112 his3-11,15 } \\
\text { ade2-1 trp1-1 ura3-1 URA3-ADE2-VIIL }\end{array}$ & $\begin{array}{l}850 \mathrm{bp}(12 \mathrm{~d}) \\
1600 \mathrm{bp}(6 \mathrm{~d}) \\
1550 \mathrm{bp} \\
(12 \mathrm{~b})\end{array}$ \\
\hline BL40-12c, BL42-3b & $\begin{array}{l}\text { MAT } \alpha \text { (MATa for } 3 \text { b) hpr } 1: \text { HIS3 rad52::TRP1 leu2-3,112 his3-11,15 } \\
\text { ade2-1 trp1-1 ura3-1 URA3-ADE2-VIIL }\end{array}$ & $1500-1660 \mathrm{bp}$ \\
\hline BL45-16aP, $23 \mathrm{cP}$ & $\begin{array}{l}\text { MAT } \alpha \text { (MATa for 23cP) rap1::LEU2 leu2-3,112 trp1 his3 ade2-1 ura3-1 } \\
\quad \text { ura3-ADE2-VIIL pRS316/rapl-17 }\end{array}$ & N.A. \\
\hline BL45-23c-P+D & $\begin{array}{l}\text { MATa rap1::LEU2 leu2-3,112 trp1 his3 ade2-1 ura3-1 ura3-ADE2-VIIL } \\
\text { pD130/RAP1 }\end{array}$ & N.A. \\
\hline BL45-23c-P + D/hprl $\Delta$ & 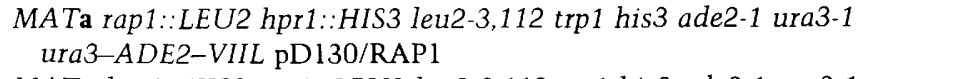 & N.A. \\
\hline BL45-29bP & 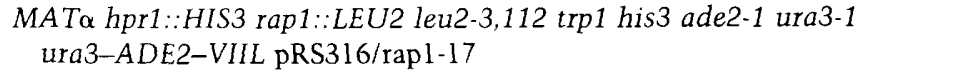 & N.A. \\
\hline $\mathrm{BL} 27-11 \mathrm{a} / \mathrm{sir} 2$ & BL27-11a with sir2::URA3 & $1720 \mathrm{bp}$ \\
\hline $\mathrm{BL} 27-11 \mathrm{a} / \operatorname{sir} 3(3,5)$ & BL27-11a with sir3::LEU2 & $1990-2070 \mathrm{bp}$ \\
\hline
\end{tabular}


Table 3. (Continued)

\begin{tabular}{|c|c|c|}
\hline Strain & Genotype & $\begin{array}{l}\text { ADE2-marked } \\
\text { telomere size }\end{array}$ \\
\hline BL27-1 la/sir4 & BL27-11 a with $\operatorname{sir} 4:: U R A 3$ & $1080 \mathrm{bp}$ \\
\hline BL27-11a/rad7 $(1,8)$ & BL27-11a with rad7::LEU2 & $1830-1920 \mathrm{bp}$ \\
\hline BL27-11a/pms1 $(3,4)$ & BL27-11a with pms1s & $2000-2050 \mathrm{bp}$ \\
\hline BL27-11a/tlcl $(1,2,6)$ & BL27-11a with tlc1::LEU2 & $1480-1560 \mathrm{bp}$ \\
\hline BL27-1 la/msh2 $\{2,3\}$ & BL27-11a with msh2::Tn10luk & $1390-1520 \mathrm{bp}$ \\
\hline BL27-11a/msh3(13,14,18,19) & BL27-11a with msh3::LEU2 & $1450-1520 \mathrm{bp}$ \\
\hline BL27-11a/hprl $(2,4,5)$ & BL27-11a with hpr1::HIS3 & $1650-1750 \mathrm{bp}$ \\
\hline BL27-11a/rth1 & BL27-11a with rth1::URA3 & $1290 \mathrm{bp}$ \\
\hline BL27-11a/tell $(1,4)$ & BL27-11a with tel1::URA3 & $1400-1600 \mathrm{bp}$ \\
\hline BL27-11a/est 1 (14) & BL27-11a with est $1:: U R A 3$ & $1300 \mathrm{bp}$ \\
\hline BL27-11a/rad5 (17) & BL27-11a with rad5::URA3 & $2000 \mathrm{bp}$ \\
\hline BL33-4c/sir3 $(3,4,9,10)$ & BL33-4c with sir3:: LEU2 & $1260-1430 \mathrm{bp}$ \\
\hline
\end{tabular}

Sources: ${ }^{a}$ Dr. Rodney Rothstein (Columbia University, New York, NY); ${ }^{b}$ Dr. David Shore (Columbia University); ${ }^{c}$ Dr. Hannah Klein (New York University, NY); ${ }^{d}$ Kyrion et al. (1993); ${ }^{\mathrm{e}}$ Liu et al. (1994). The numbers in parentheses adjacent to the BL27-11a series of strains are transformant designations. (N.T.) Not tested; (N.A.) not applicable.

$\mathrm{mm}$ diam.) were picked and inoculated into $5 \mathrm{ml}$ of YPAD liquid media. The overnight culture was used for DNA isolation to determine the length of the $A D E 2$-marked telomere.

2. Liquid subculturing for assaying cumulative deletion hpr 1 and hpr 1 sir 3 cells were inoculated into $5 \mathrm{ml}$ of YPAD liquid media and serially subcultured for three rounds, with each round of growth representing two to three generations. For detecting slower rates of TRD in wild-type cells carrying $50 \%$ or $100 \%$ elongated telomeres, cells were inoculated into $20 \mathrm{ml}$ of YPAD liquid media and subcultured for three rounds, with each round representing 7-10 doublings.

The frequency of telomere deletion per generation, $x$, was calculated from the following parameters: $T$, the number of cells at the end of the first subculture; $U_{i}$, the percentage of cells that have undeleted forms of the marked telomere after the $i$ th subculture ( $i=1$ or 2$)$; and, $n$, the number of population doublings during the second subculture. $1-X$ represents the fraction of undeleted forms/generation. Therefore, the number of undeleted telomeres at the end of the second subculture can be expressed as $\left[T^{\star} U_{1} *(1-x)^{n *} 2^{n}\right]$. Because $T^{\star} 2^{n}$ represents the total number of cells at the end of the second subculture, $U_{2}=\left[T^{\star} U_{1}^{*}(1-x)^{n \star} 2^{n}\right] /\left[T^{\star} 2^{n}\right]$. Hence, $x=1-\left(U_{2} / U_{1}\right)^{1 / n}$, where $n=\log _{2}\left(O D_{f} / O D_{s}\right)$, and $O D_{s}$ and $\mathrm{OD}_{\mathrm{f}}$ are the $\mathrm{OD}_{600}$ values before and after subculturing, respectively. The $U_{\mathrm{i}}$ values were determined by quantitation of Southern blot by use of a $\beta$-scope (Betagen), where $U_{\mathrm{i}}=\mathrm{cpm}$ undeleted telomere species divided by cpm undeleted + deleted telomeric species.

\section{Statistical analysis}

The mean rate of TRD per cell division with the color assay was calculated by the method of the median (Lea and Coulson 1948). The statistical significance among different mean values obtained in multiple trials was determined by Rank Sum and $\mathrm{T}$ tests (Snedecor and Cochran 1980).

\section{Acknowledgments}

We thank Andres Aguilera, Daniel Geitz, Dan Gottschling, Hannah Klein, Robert Lahue, Tom Petes, David Shore, Miriam Singer, Rolf Sternglanz, and Raymond Wellinger for providing plasmids; Hannah Klein and Rodney Rothstein for providing yeast strains; Chen Zhang and Stephanie Lin for excellent technical assistance; and Titia de Lange, John Hanish and E. B. Hoffman for critical comments on the manuscript. These studies were funded by a grant (MCB9318918) from the National Science Foundation (to A.J.L.) and an NCI Cancer Center support grant (NCI-P30-CA-8748) to MSKCC.

The publication costs of this article were defrayed in part by payment of page charges. This article must therefore be hereby marked "advertisement" in accordance with 18 USC section 1734 solely to indicate this fact.

\section{References}

Aguilera, A. and H. Klein. 1989. Genetic and molecular analysis of recombinant events in Saccharomyces cerevisiae occurring in the presence of the hyper-recombination mutation hpr1. Genetics 122: 503-517.

. 1990. HPR1, a novel yeast gene that prevents intrachromosomal excision recombination, shows carboxy-terminal homology to the Saccharomyces cerevisiae TOP1 gene. Mol. Cell. Biol. 10: 1439-1451.

Bardwell, A., L. Bardwell, A. Tomkinson, and E. Friedberg. 1994. Specific cleavage of model recombination and repair intermediates by the yeast Radl-Rad10 DNA endonuclease. Science 265: 2082-2085.

Bernards, A., P. Michels, C. Lincke, and P. Borst. 1983. Growth of chromosome ends in multiplying trypanosomes. Nature 303: 592-597.

Bryan, T., A. Englezou, J. Gupta, S. Bacchetti, and R. Reddel. 1995. Telomere elongation in immortal human cells without detectable telomerase activity. EMBO I. 14: 4240-4248.

Chien, C.-T., P. Bartel, R. Sternglanz, and S. Fields. 1991. The two-hybrid system: A method to identify and clone genes for proteins that interact with a protein of interest. Proc. Natl. Acad. Sci. 88: 9578-9582.

Chien, C.-T., S. Buck, R. Sternglanz, and D. Shore. 1993. Targeting of Sirl protein establishes silencing at $H M$ loci and telomeres in yeast. Cell 75: 531-541.

Christman, M., F. Dietrich, and G. Fink. 1988. Mitotic recombination in the rDNA of $S$. cerevisiae is suppressed by the combined action of DNA topoisomerases I and II. Cell 55: 413-425. 
Cockell, M., F. Palladino, T. Laroche, G. Kyrion, C. Liu, A.J. Lustig, and S.M. Gasser. 1995. The carboxy termini of Sir4 and Rap1 affect Sir3 localization: Evidence for a multi-component complex required for telomeric silencing. J. Cell Biol. 129: 909-924.

Cohn, M. and E. H. Blackburn. 1995. Telomerase in yeast. Sci. ence 269: 396-400.

Conrad, M., J. Wright, A. Wolf, and V.A. Zakian. 1990. RAPl protein interacts with yeast telomeres in vivo: Overproduction alters telomere structure and decreases chromosome stability. Cell 63: 739-750.

Dernberg, A., J. Sadat, W. Cande, and H. Baas. 1995. Cytology of telomeres. In Telomeres (ed. E. Blackburn and C. Greider), pp. 295-338. Cold Spring Harbor Laboratory Press, Cold Spring Harbor, NY.

Garvik, B., M. Carson, and L. Hartwell. 1995. Single-stranded DNA arising at telomeres in $c d c 13$ mutants may constitute a specific signal for the RAD9 checkpoint. Mol. Cell. Biol. 15: 6128-6138.

Gilson, E. and S. M. Gasser. 1995. Repressor activator protein I and its ligands: Organising chromatin domains. Nucleic Acids Mol. Biol. 9: 308-327.

Gilson, E., M. Roberge, R. Giraldo, D. Rhodes, and S.M. Gasser. 1993. Distortion of the DNA double helix by RAPl at silencers and multiple telomeric binding sites.. . Mol. Biol. 231: 293-310.

Gottschling, D., O. Aparicio, B. Billington, and V.A. Zakian. 1990. Position effect at S. cerevisiae telomeres: Reversible repression of Pol II transcription. Cell 63: 751-762.

Greenwell, P., S. Kronmal, S. Porter, J. Gassenhuber, B. Overmaier, and T.D. Petes. 1995. TEL1, a gene involved in controlling telomere length in S. cerevisiae, is homologous to the human ataxia telangiesctasia gene. Cell 82: 823-829.

Greider, C. 1995. Telomerase biochemistry and regulation. In Telomeres (ed. E. Blackburn and C. Greider), pp. 35-68. Cold Spring Harbor Laboratory Press, Cold Spring Harbor, NY.

Haber, J. 1992. Exploring the pathways of homologous recombination. Curr. Opin. Cell Biol. 4: 401-412.

Johnson, R., S. Henderson, T.D. Petes, S. Prakash, M. Bankmann, and L. Prakash. 1992. Saccharomyces cerevisiae $R A D 5$-encoded DNA repair protein contains DNA helicase and zinc-binding sequence motifs and affects the stability of simple repetitive sequences in the genome. Mol. Cell. Biol. 12: 3807-3818.

Johnson, R., G. Kovvali, L. Prakash, and S. Prakash. 1995. Requirement of the yeast RTH1 $5^{\prime}$ to $3^{\prime}$ exonuclease for the stability of simple repetitive DNA. Science 269: 238-240.

Kaiser, C.S., S. Michaelis, and A. Mitchell. 1994. Methods in yeast genetics. Cold Spring Harbor Laboratory Press, Cold Spring Harbor, NY.

Klein, F., T. Laroche, M. Cardenas, F.-X. Hofmann, D. Schweizer, and S.M. Gasser. 1992. Localization of RAP1 and topoisomerase II in nuclei and meiotic chromosomes of yeast. J. Cell. Biol. 117: 935-948.

Klein, H. 1995. Genetic control of intrachromosomal recombination. BioEssays 17: 147-159.

Kurtz, S. and D. Shore. 1991. The RAP1 protein activates and silences transcription of mating-type genes in yeast. Genes \& Dev. 5: 616-628.

Kyrion, G., K. Boakye, and A.J. Lustig. 1992. C-terminal truncation of RAP1 results in the deregulation of telomere size, stability and function in Saccharomyces cerevisiae. Mol. Cell. Biol. 12: 5159-5173.

Kyrion, G., K. Liu, C. Liu, and A.J. Lustig. 1993. RAP1 and telomere structure regulate telomere position effects in Saccharomyces cerevisiae. Genes \& Dev. 7: 1146-1159.
Larson, D., E. Spangler, and E.H. Blackburn. 1987. Dynamics of telomere length variation in Tetrahymena thermophila. Cell 50: $477-483$.

Lea, D. and C. Coulson. 1948. The distribution of the numbers of mutants in bacterial populations. I. Genet. 49: 226-284.

Lingner, J., J. Cooper, and T.R. Cech. 1995. Telomerase and DNA end replication: No longer a lagging strand problem? Science 269: 1533-1534.

Lin, J.-J. and V.A. Zakian. 1995. An in vitro assay for Saccharomyces telomerase requires EST1. Cell 81: 1127-1135.

Liu, C., X. Mao, and A.J. Lustig. 1994. Mutational analysis defines a C-terminal tail domain of RAPl essential for telomeric silencing in Saccharomyces cerevisiae. Genetics 138: 1025-1040.

Longtine, M., N. Wilson, M. Petracek, and J. Berman. 1989. A yeast telomere binding activity binds to two related telomere sequence motifs and is indistinguishable from RAPl. Curr. Genet. 6: 225-240.

Lue, N. and J. Wang. 1995. ATP-dependent processivity of a telomerase activity from Saccharomyces cerevisiae. I. Biol. Chem. 270: 21453-21456.

Lundblad, V. and J. Szostak. 1989. A mutant with a defect in telomere elongation leads to senescence in yeast. Cell 57: 633-643.

Lustig, A.J. and T.D. Petes. 1986. Identification of yeast mutants with altered telomere structure. Proc. Nat. Acad. Sci. 83: 1398-1402.

Lustig, A.J., C. Liu, C. Zhang, and J.P. Hanish. 1996. Tethered Sir3p nucleates silencing at telomeres and internal loci in Saccharomyces cerevisiae. Mol. Cell. Biol. 16: 2483-2495.

McEachern, M. and E.H. Blackburn. 1995. Runaway telomere elongation caused by telomerase RNA gene mutations. $\mathrm{Na}$ ture 376: 403-409.

Melek, M., E.C. Greene, and D.E. Shippen. 1996. Processing of non-telomere 3 ' ends by telomerase: Default template alignment and endonucleolytic cleavage. Mol. Cell. Biol. (in press).

Moretti, P., K. Freeman, L. Coodly, and D. Shore. 1994. Evidence that a complex of SIR proteins interacts with the silencer and telomere-binding protein RAP1. Genes \& Dev. 8: 2257-2269.

Murnane, J., L. Sabatie, B. Marder, and W. Morgan. 1994. Telomere dynamics in an immortal human cell line. EMBO I. 13: 4953-4962.

Paetkau, D., J. Riese, W. MacMorran, R. Woods, and R. Gietz. 1994. Interaction of the yeast RAD7 and SIR3 proteins: Implications for DNA repair and chromatin structure. Genes \& Dev. 8: 2035-2045.

Palladino, F., T. Laroche, E. Gilson, A. Axelrod, L. Pillus, and S.M. Gasser. 1993. SIR3 and SIR4 proteins are required for the positioning and integrity of yeast telomeres. Cell 75: 543-555.

Petes, T.D., R. Malone, and L. Symington. 1991. Recombination in yeast. In The molecular and cellular biology of the yeast Saccharomyces (ed. J. Broach, J. Pringle, E. Jones), Vol. 1, pp. 407-522. Cold Spring Harbor Laboratory Press, Cold Spring Harbor, NY.

Reenan, R. and R. Kolonder. 1992. Isolation and characterization of two Saccharomyces cerevisiae genes encoding homologs of the bacterial HexA and MutS mismatch repair proteins. Genetics 132: 963-985.

Roth, M. and D. Prescott. 1985. DNA intermediates and telomere addition during genome reorganization in Euplotes crassus. Cell 41: 411-417.

Santos-Rosa, H. and A. Aguilera. 1994. Increase in incidence of chromosome stability and non-conservative recombination between repeats in Saccharomyces cerevisiae hpr1s strains. 
Mol. \& Gen. Genet. 245: 224-236.

Selva, E., L. New, G. Crouse, and R. Lahue. 1995. Mismatch correction acts as a barrier to homeologous recombination in Saccharomyces cerevisiae. Genetics 139: 1175-1188.

Shampay, J. and E.H. Blackburn. 1988. Origins of telomere length heterogeneity in S. cerevisiae. Proc. Natl. Acad. Sci. 85: 534-538.

Shore, D. 1994. RAPl: A protean regulator in yeast. Trends Genet. 10: 408-412.

1995. Telomere position effects and transcriptional silencing in the yeast Saccharomyces cerevisiae. In Telomeres (ed. E. Blackburn and C. Greider), pp. 139-191. Cold Spring Harbor Laboratory Press, Cold Spring Harbor, NY.

Shore, D., M. Squire, and K. Nasmyth. 1984. Characterization of two genes required for the position-effect control of yeast mating-type genes. $E M B O$ I. 3: 2817-2824.

Singer, M. and D. Gottschling. 1994. TLC1: Template RNA component of Saccharomyces cerevisiae telomerase. Science 266: 398-404.

Snedecor, G. and W. Cochran. 1980. Statistical methods, 7th ed., The Iowa State University Press, Ames, IA.

Stone, E., M. Swanson, A. Romeo, J. Hicks, and R. Sternglanz. 1991. The SIR1 gene of Saccharomyces cerevisiae and its role as an extragenic suppressor of several mating-defective mutations. Mol. Cell. Biol. 11: 2253-2262.

Strand, M., T. Prolla, R. Liskay, and T.D. Petes. 1993. Destabilization of tracts of simple repetitive DNA in yeast by mutations affecting DNA mismatch repair. Nature 365: 274-276.

Strand, M., M. Earley, G. Crouse, and T.D. Petes. 1995. Mutations in the MSH3 gene preferentially lead to deletions within tracts of simple repetitive DNA in Saccharomyces cerevisiae. Proc. Natl. Acad. Sci. 92: 10418-10421.

Tomkinson, A., A. Bardwell, L. Bardwell, N. Tappe, and E. Friedberg. 1993. Yeast DNA repair and recombination proteins Radl and Rad 10 constitute a single-strand DNA endonuclease. Nature 362: 860-862.

Verhage, R., A. Zeeman, N. deGroot, F. Gleig, D. Bang, P. van de Putte, and J. Brower. 1994. The RAD7 and RAD16 genes, which are essential for pyrimidine dimer removal from the silent mating type loci, are also required for repair of the nontranscribed strand of an active gene in Saccharomyces cerevisiae. Mol. Cell. Biol. 14: 6135-6142.

Wallis, J., G. Chrebet, G. Brodsky, M. Rolfe, and R. Rothstein. 1989. A hyper-recombination mutation in S. cerevisiae identifies a novel eukaryotic topoisomerase. Cell 58: 409-419.

Walmsley, R. and T.D. Petes. 1985. Genetic control of chromosome length in yeast. Proc. Natl. Acad. Sci. 82: 506-510.

Wright, J., D. Gottschling, and V.A. Zakian. 1992. Saccharomyces telomeres assume a non-nucleosomal chromatin structure. Genes \& Dev. 6:197-210.

Zahler, A. and D. Prescott. 1988. Telomere terminal transferase activity in the hypotrichous ciliate Oxytricha nova and a model for replication of the ends of linear DNA molecules. Nucleic Acids Res. 16: 6953-6972.

Zakian, V.A. 1995a. Telomeres: Beginning to understand the end. Science 270: 1601-1607

__ . 1995b. Saccharomyces telomeres: Function, structure, and replication. In Telomeres (ed. E. Blackburn and C. Greider|, pp. 107-137. Cold Spring Harbor Laboratory Press, Cold Spring Harbor, NY.

Zhu, Y., C. Peterson, and M. Christman. 1995. HPR1 encodes a global positive regulator of transcription in Saccharomyces cerevisiae. Mol. Cell. Biol. 15: 1698-1708. 


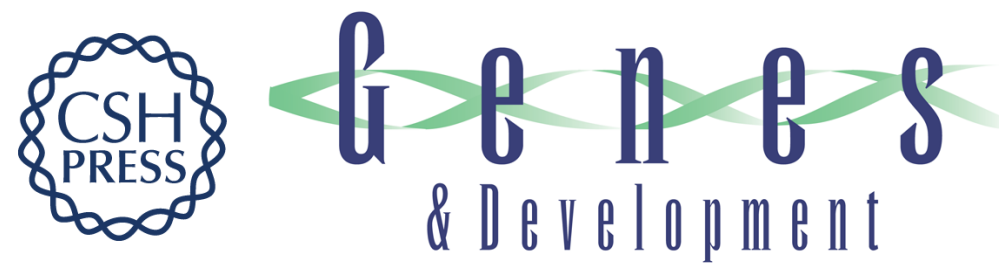

\section{A novel mechanism for telomere size control in Saccharomyces cerevisiae.}

$B$ Li and A J Lustig

Genes Dev. 1996, 10:

Access the most recent version at doi:10.1101/gad.10.11.1310

References This article cites 58 articles, 30 of which can be accessed free at:

http://genesdev.cshlp.org/content/10/11/1310.full.html\#ref-list-1

License

Email Alerting

Service

Receive free email alerts when new articles cite this article - sign up in the box at the top right corner of the article or click here.

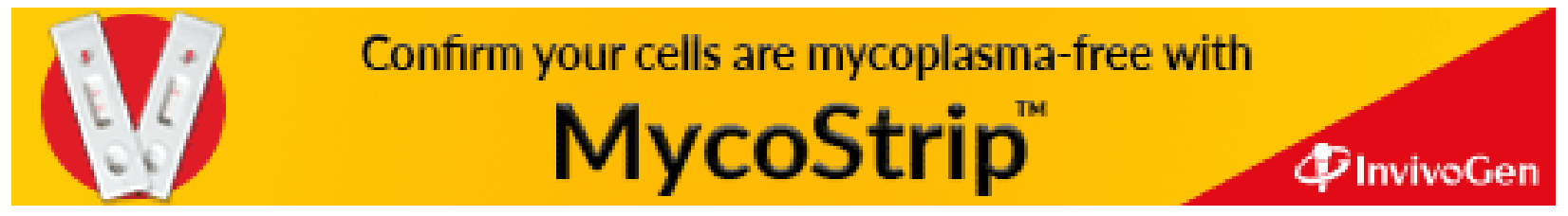

